This item was submitted to Loughborough's Research Repository by the author.

Items in Figshare are protected by copyright, with all rights reserved, unless otherwise indicated.

\title{
An investigation into future performance and overheating risks in Passivhaus dwellings
}

PLEASE CITE THE PUBLISHED VERSION

http://dx.doi.org/10.1016/j.buildenv.2013.08.024

PUBLISHER

(C) Elsevier

VERSION

AM (Accepted Manuscript)

\section{PUBLISHER STATEMENT}

This work is made available according to the conditions of the Creative Commons Attribution-NonCommercialNoDerivatives 4.0 International (CC BY-NC-ND 4.0) licence. Full details of this licence are available at: https://creativecommons.org/licenses/by-nc-nd/4.0/

\section{LICENCE}

CC BY-NC-ND 4.0

\section{REPOSITORY RECORD}

McLeod, Robert S., Christina J. Hopfe, and Alan Kwan. 2019. "An Investigation into Future Performance and Overheating Risks in Passivhaus Dwellings”. figshare. https://hdl.handle.net/2134/21869. 


\title{
An investigation into future performance and overheating risks in Passivhaus dwellings
}

\author{
Robert S. MCLEOD*, Christina J. HOPFE, AlAN KWAN
}

* Corresponding author.

\begin{abstract}
In response to UK government policy mandating the construction of 'zero carbon' homes by 2016 there have been significant changes in the way dwellings are being designed and built. Recent years have seen a rapid uptake in the adoption of the German Passivhaus standard as a template for ultralow energy and zero carbon buildings in the UK. Despite genuine motivations to mitigate climate change and fuel poverty there is a lack of research investigating the long-term performance of Passivhaus buildings in a rapidly changing UK climate. This paper sets out to investigate whether Passivhaus dwellings will be able to provide high standards of thermal comfort in the future or whether they are inherently vulnerable to overheating risks. Scenario modelling using probabilistic data derived from the UKCP09 weather generator (WG) in conjunction with dynamic simulation and global sensitivity analysis techniques are used to assess the future performance of a range of typical Passivhaus dwellings relative to an identical Fabric Energy Efficiency Standard (FEES) compliant dwelling over its notional future lifespan. The emphasis of this study is to understand what impact climate change will pose to overheating risks for Passivhaus dwellings relative to the de facto (i.e. FEES) alternative, and which design factors play a dominant role in contributing to this risk. The results show that optimization of a small number of design inputs, including glazing ratios and external shading devices, can play a significant role in mitigating FUTURE OVERHEATING RISKS
\end{abstract}

\section{INTRODUCTION}

In response to the UK government's overarching climate change mitigation strategy (Defra, 2007; $H M, 2011$ ) and the recast European Energy Performance in Buildings Directive (EPBD) (EU, 2010) targets have been set for the implementation of a revised 'zero carbon' dwelling standard in the UK by 2016 (DCLG, 2011; ZCH, 2011; McLeod et al., 2012). As a result of these legislative drivers and the voluntary adoption of advanced performance standards, such as the Passivhaus standard, there have been significant changes in the way dwellings are being designed and constructed both in the UK and across Europe.

Over the past decade the evolution of Approved Document L1A (Conservation of fuel and power for new dwellings) of the UK Building Regulations (HM, 2010) has prioritised incrementally reducing space heating consumption, since this has historically dominated the $\mathrm{CO} 2$ emissions profile of UK dwellings (DECC, 2012). Attempts to further reduce energy consumption and $\mathrm{CO} 2$ e emissions in Passivhaus, FEES and advanced performance standards have largely focused on reducing thermal transmission losses and making optimal use of passive solar gains (Feist et al., 2012; ZCH, 2009) whilst less attention has been paid to whole-life performance issues such as long-term thermal comfort and occupant wellbeing. Implementation of these advanced performance standards is taking place against a background of rapid climatic change. Bows and Anderson (2008) suggest that a revised interpretation of atmospheric $\mathrm{CO} 2$ e concentration indicates that stabilization much below $650 \mathrm{ppmv}$ by the end of this century is now improbable. Earlier predictions by Meinshausen (2006) estimated the mid-range probability of exceeding a 4 _C threshold at approximately 40 per cent for 
650 ppmv. Bows and Anderson (2008, p. 18) state that "given this analysis has not factored in a range of other issues with likely net positive impacts, adapting for estimated impacts of at least 4 _C appears wise." A 4 _C, average global temperature, increase by the end of this century is consistent with the Intergovernmental Panel on Climate Change (IPCC) best estimate for the A1FI trajectory, commonly known as the 'High' emission scenario, ((IPCC, 2007); Table 3.1). Reframing likely emissions in this light suggests that modelling the impacts of the A1FI scenario on the built environment can no longer be regarded as a cautionary approach. The risk of perverse consequences in the form of exacerbated overheating risks in super insulated Passivhaus dwellings have been highlighted in a number of Northern European ( Isaksson and Karlson, 2006; Janson, 2010; Larsen and Jensen, 2011, Person, 2012)), Central European (Ginkel, 2007; Hasselaar, 2008; Schmitt et al, 2007) and Southern European (Schnieders, 2005; Schnieders, 2009) reports. Larsen and Jensen (2011, p. 1) conclude that, "the large focus on energy performance has reduced the focus on indoor environment.

This has amongst other problems, resulted in problems with overheated buildings". These finding suggests that there may be anemerging conflict between the implementation of such standards and the policy recommendations set out in Article 4 of the recast EPBD, which states; "These requirements shall take account of general indoor climate conditions, in order to avoid possible negative effects." (EU, 2010, p. 19).

Despite documented reports of overheating in UK (and neighbouring Republic of Ireland) Passivhaus dwellings (Bere, 2012; Passive House Builders, 2013) the subject has received only scant consideration in the scientific literature. However as attention focuses on the development of a national methodology to meet the 2016 'Zero Carbon' target, awareness of the potential for unintended consequences associated with super-insulated airtight dwellings is mounting. In 2010 the Zero Carbon Hub $(\mathrm{ZCH})$ cautioned that, "There is some anxiety that homes we are building today may be at risk of overheating even in the current climate. Given the prospect of significant warming, well within the expected lifetime of homes, this risk will increase with potentially serious consequences". (ZCH, 2010a, p. 7). In a comprehensive review of the evidence of overheating in new UK homes, Dengel and Swainson conclude that there is, "a growing body of evidence that modern energy efficient, i.e. well insulated, airtight dwellings are suffering from overheating, and that in some cases this is resulting in adverse health effects for the occupants of these properties" (NHBC, 2012a, p. 19). In light of these findings, this paper sets out to answer three questions that are central to gaining a better understanding of these issues:

1) Do Passivhaus dwellings, as currently designed in the UK, offer a robust model in the face of future climatic changes?

2) Will Passivhaus dwellings perform better or worse than an equivalent FEES 'Zero Carbon' dwelling faced with identical climatic change scenarios?

3) What are the key design variables influencing the future performance of Passivhaus dwellings?

\section{BACKGROUND- AN OVERVIEW OF PASSIVHAUS AND LOW ENERGY BUILDING PERFORMANCE}

The Passivhaus standard is generally considered to be a low energy building performance standard; characterised by super insulated, airtight envelopes, the use of mechanical ventilation with heat 
recovery (MVHR) and optimal use of passive solar gains. However, achieving clearly defined thermal comfort criteria are also central to the concept. The functional definition of a Passivhaus, states that:

"A Passive House is a building in which thermal comfort can be guaranteed solely by heating or cooling of the supply air which is required for sufficient indoor air quality - without using additional recirculated air" (Feist, 2007; iPHA, 2013).

A detailed description of the technical requirements for achieving quality approved Passivhaus status are described in the Passive House Planning Package, Version 7 (Feist et al., 2012). The adoption of the Passivhaus concept in the UK is a relatively recent occurrence, with the first certified Passivhaus buildings being completed in 2010 (iPHA, 2013); as a result only minimal post occupancy data is available to date. Elsewhere in Europe a number of studies that have reported on overheating risks in Passivhaus dwellings and the key findings are summarised in Section 4.1.1. Climate change and heat waves are likely to have significant implications for the future UK built environment and the main findings are summarised in Section. 4.1.2. Thermal comfort and the impacts of overheating on human health are issues which are central to the assessment of future overheating risks, and the main implications are summarised in Section 4.1.3.

\subsection{OVERHEATING RISK IN PASSIVHAUS BUILDINGS}

A number of studies have reported specifically on overheating and the summer performance of Passivhaus buildings in a variety of European climatic zones. A finding common to many of these studies is that the occupants of Passivhaus dwellings often report better thermal comfort in winter than in summer (Berndgen-Kaiser et al., 2007; Danner and Vittar, 2001; Mlecnik et al., 2012; Wagner and Mauthner, $2008 \mathrm{a}$; Wagner and Mauthner, 2008b) . Contrary to this finding, there are also a number of reports, based on Post Occupancy Evaluations (POEs) and monitoring carried out by the Passivhaus Institute, indicating high levels of occupant satisfaction under summer conditions (Schnieders et al., 2001; Hermelink and Hübner, 2003; Hermelink, 2004; Schnieders and Hermelink, 2006; Feist et al., 2012).

Studies documenting overheating in certified Passivhaus buildings located in Northern Europe warrant further investigation since they are of considerable relevance to the UK climatic context. In Skibet, Denmark, Larsen and Jensen (Larsen and Jensen, 2011) carried out data logging of the internal environment of 10 certified Passivhaus dwellings. The Skibet development is located at 55.7 North (a latitude which is slightly south of Glasgow, UK). They recorded data for dry bulb temperature $\left(T_{d b}\right)$, relative humidity $(\mathrm{RH})$ and $\mathrm{CO}_{2}$ levels in multiple locations from 2008 to 2011. 
The data recorded in this study was then compared to the criteria set out in category B of DS/CEN/CR1752 (2001), which specifies an acceptable summertime dry bulb range from $23-26^{\circ} \mathrm{C}$. The results for the month of July for the 2009 interval show that this criterion was exceeded $40 \%$ of the time. In 2010 the same criteria was exceeded $60 \%$ of the time, resulting in severe overheating (Larsen and Jensen, 2011). One factor contributing to the difference in the duration of overheating was attributed to different occupant ventilation patterns and another to different weather patterns experienced over the two summer periods. What is notable is that such a prolonged overheating risk was not predicted by the PHPP model of the certified dwellings, however it was subsequently replicated by a dynamic simulation programme (DSP) BSim (DBRI, 2013) and also via manual calculation in accordance with SBI instruction 202 (Andersen et al, 2002).

A similar study carried out in Lindås, Sweden showed that mean summer temperatures of $25.2^{\circ} \mathrm{C}$ were recorded in a group of 20 terraced apartments built to the Passivhaus standard (Ruud and Lundin, 2004). Significant variability was recorded in the internal temperatures between apartments with some recording acceptable conditions and others reaching internal temperatures of up to $30^{\circ} \mathrm{C}$ in summer. Further Post Occupancy surveys carried out in the Oxtorget, Glumslöv and Frillesås districts of Sweden also reported thermal discomfort due to overheating. In the worst case, $56 \%$ of the Passivhaus residents in the Glumslöv district reported their indoor temperature as too warm during the summer period (Samuelson and Lüddeckens, 2009).

By examining the performance of Passivhaus dwellings in climatic zones that are already warmer than the present day UK climate, it might be possible to infer the likely impacts of future climatic change. However, few studies have investigated the performance of dwellings built to a full Northern European Passivhaus specification in a Southern European context (primarily, because they are seldom built to the same specification). As part of the Passive-On project, Schnieders (2005) set out to determine the optimal performance characteristics of a cost efficient model of a Passivhaus dwelling located in Marseille. In this study Schnieders used a DSP model (Dynbil) to simulate the performance of an end-terrace Passivhaus, based upon a design previously used in the HannoverKronsberg development (Feist et al, 2005) . Four variants of the 'First Guess' Passivhaus were modelled to assess performance differences between the use of a well-insulated fabric $U$ values ( $\leq$ $0.15 \mathrm{~W} / \mathrm{m}^{2} \mathrm{~K}$ ) with a less well insulated alternative $\mathrm{U}$ values (circa $0.25 \mathrm{~W} / \mathrm{m}^{2} \mathrm{~K}$ ). The buildings were modelled with both double ( $\mathrm{U}$ value $1.19 \mathrm{~W} / \mathrm{m}^{2} \mathrm{~K}$, g value 0.64 ) and triple glazing ( $\mathrm{U}$ value 0.71 $\mathrm{W} / \mathrm{m}^{2} \mathrm{~K}, \mathrm{~g}$ value 0.5$)$ options, with and without heat recovery ventilation $\left(\mu_{\mathrm{HR}}=0.75\right)$ using a typical weather year (ASHRAE, 2001) for Marseille. The maximum temperature in this weather year is $34^{\circ} \mathrm{C}$ with a summer monthly average of around $25^{\circ} \mathrm{C}$ (Schnieders, 2005). The findings of this study are 
interesting because they show that over the year the dwelling with the lowest annual heating demand resulted from the least insulated fabric ( $U$ values $\approx 0.25 \mathrm{~W} / \mathrm{m}^{2} \mathrm{~K}$ ) and in conjunction with double-glazing (U value $1.19 \mathrm{~W} / \mathrm{m}^{2} \mathrm{~K}, \mathrm{~g}$ value 0.64 ) and no heat recovery system. In term of overheating mitigation all dwellings were modelled with night purge ventilation and automated external blinds. Despite these interventions the goal of not exceeding the overheating threshold, defined by the $\mathrm{PHI}$ as $25^{\circ} \mathrm{C}$ for $10 \%$ of the year (Feist et al., 2012) was not be met in any of the prototypes. Furthermore, without active cooling, maximum temperatures exceeding $27^{\circ} \mathrm{C}$ were recorded in bedrooms. However when cooling was applied to maintain the supply air temperature below $25^{\circ} \mathrm{C}$, the well-insulated triple glazed variant with Heat Recovery ventilation recorded a slightly lower cooling demand than the other variants (Schnieders, 2005).

In a larger study Schnieders (2009) used different thermal specifications, and cooling strategies to examine the feasibility of the Passivhaus concept in twelve different reference locations across Southern Germany, Italy, Southern France and the Iberian Peninsula. Schnieders concludes that the Passivhaus concept is able to provide a comfortable indoor climate, in accordance with EN/ISO 7730 (2006) in all twelve locations exclusively by pre-conditioning (i.e. active cooling of) the supply airflow. Schnieders points out that (in summer) solar control; via external shading, reduction of solar load through opaque elements and minimising internal heat loads are decisive characteristics in maintaining thermal comfort. Night purge ventilation and to a lesser extent ground coupling were considered critical factors in removing heat from the building, with supply air cooling providing the remaining cooling and dehumidification requirement. Carrilho da Graça et al (2012) came to similar conclusions in a comparative study of two Net Zero Energy Home (NZEH) prototypes in a Southern European context (Lisbon). Comparing a conventional highly glazed NZEH (using internal shading) with an almost identical moderately glazed Passivhaus (using external shading) Carrilho da Graḉa et al (2012) found that the highly glazed house had substantially higher overheating risks, with living room temperatures exceeding $28^{\circ} \mathrm{C}$ for more than $46 \%$ of the summer season. In contrast, the externally shaded Passivhaus rarely exceeded this threshold.

In addition to the heating and cooling demands being lower than for conventional dwellings Schnieders (2009) found that the peak heating and cooling loads where also less pronounced and internal temperature fluctuations were lower regardless of whether active cooling was applied. From a design perspective, Schnieders cautioned, "it is important to note that the differences in climates and the effects of individual building parameters are so large that a dedicated energy balance must be set up for every Passive House. The use of standard values for different buildings is 
not appropriate" (Schnieders, 2009, p279). These findings highlight the parametric sensitivity of Passivhaus and ultra-low energy buildings, reinforcing the need to study these issues in context.

Evidence suggests that the overheating risks in Passivhaus dwellings are highly dependent on context, and are strongly influenced by both user behaviour; including ventilation patterns, shading strategies and internal gains (Larsen and Jensen, 2011; Wagner and Mauthner, 2008a; Wagner and Mauthner, 2008b) as well as the building's thermal specification (Schnieders, 2005; Schnieders, 2009). Notably in almost every case external shading was required to maintain summer thermal comfort. Schnieders DSP modelling in a South West European context was predicated upon automated external shutters closing whenever the ambient temperature exceeded $23^{\circ} \mathrm{C}$ (Schnieders, 2009, p268). Relatively little is known about the acceptability of such strategies to domestic occupants. A number of authors (Raja et al., 2001; Nicol, 2001; Inkarojit, 2005; Voss et al., 2005) have suggested that the operation of blinds is determined primarily by visual comfort requirements and not by indoor temperature; however, all of these studies have assessed non-residential buildings. To date full external shading devices have been seldom used in UK residential buildings. A recent post occupancy evaluation of the Welsh, Larch and Lime, Passivhaus dwellings supports the finding that occupant use of external shading devices is driven by visual and psychological comfort criteria and not temperature regulation (Bere Architects, 2012).

\subsection{A Changing Climate And its Impact on BuILDings}

Observed climatic trends for the UK show that, between 1961 and 2006, maximum summer temperatures across the South East had increased by $2^{\circ} \mathrm{C}$ on average and in Greater London by up to $2.7^{\circ} \mathrm{C}$ (Jenkins et al., 2007). According to the United Kingdom Climate Projections (UKCP09) even under a Medium emissions scenario by 2080 the summer average temperature (at the $50^{\text {th }}$ percentile) is estimated at $5.4^{\circ} \mathrm{C}$ higher than the $1961-1990$ baseline $\left(2.2\right.$ to $9.5^{\circ} \mathrm{C}, 10^{\text {th }}-90^{\text {th }}$ percentile) in parts of southern England. Summer mean cloud cover is predicted to decrease over this period by up to $-18 \%$ (-33 to $-2 \%, 10^{\text {th }}-90^{\text {th }}$ percentile) in parts of southern UK, resulting in an extra $+16 \mathrm{Wm}^{-2} \quad\left(-2\right.$ to $+37 \mathrm{Wm}^{-2}, 10^{\text {th }}-90^{\text {th }}$ percentile $)$ flux in downward shortwave radiation (Jenkins et al., 2010).

Along with the overall warming trend and higher irradiation levels suggested by these probabilistic estimates, the frequency of extreme weather events including heat waves is also predicted to increase. According to the UK Office of National Statistics during a ten-day period in August 2003 more than 2000 excess mortalities occurred in England and Wales as a result of a heat wave (ONS, 2003). Persons over 75 years of age, in London, were the most severely affected group during this 
period with an excess mortality rate $59 \%$ higher than reference levels (Johnson et al., 2005). Although the term 'heat wave' does not have a generally accepted definition in the UK, one study proposed a working definition as "a continuous set of days when the average temperature was above $20^{\circ} \mathrm{C}$ " (Hajat et al., 2002). Hajet et al (2002) proposed a more precise definition based on the three-day rolling average value (at the 97 th percentile value) exceeding $21.5^{\circ} \mathrm{C}$. Whilst the UK Health Protection Agency have defined a heat wave as a period when daily mean temperatures on the current day, and at least the previous two days are above the $98^{\text {th }}$ percentile of the whole year temperature distribution (Vardoulakis and Heaviside, 2012). According to this definition, a present day heat-wave in London would correspond to daily mean temperatures of $22.6^{\circ} \mathrm{C}$ or higher occurring for three of more days.

During the 2003 heat wave, maximum daily Central England Temperature (CET) exceeded the baseline $(1971-2000)$ reference values by $8^{\circ} \mathrm{C}$. In London a daily maximum of $37.9^{\circ} \mathrm{C}$ was recorded with overnight lows as high as $26-27^{\circ} \mathrm{C}$ in some areas (Johnson et al., 2005). In a monitored study carried out during this heat wave Wright et al (2005) compared internal temperatures in four blocks of London flats and one semi-detached dwelling. They found that average internal temperatures were above $27^{\circ} \mathrm{C}$ in every room in all of the dwellings throughout the weeklong monitoring period. In one block of flats, the mean internal temperature was recorded as $29.9^{\circ} \mathrm{C}$ during this period (peaking at $39.2^{\circ} \mathrm{C}$ ).

Although the occurrence of 'heat wave' events is currently infrequent Met Office predictions suggests that by the $2080^{\prime} \mathrm{s}$ daytime summer temperatures might exceed $42^{\circ} \mathrm{C}$ in lowland England as often as once a decade, under a 'High' emissions scenario (Wright et al., 2005). As a consequence it is likely that previous maximum temperature records will be more frequently exceeded in a changing climate (Rahmstorf and Coumou, 2011). Met Office analysis (Jones et al., 2008) indicates that by 2040 the heat wave of 2003 could reflect average summer conditions. By 2060 this same event would represent a cooler than average summer under a Medium-high (A2) emissions scenario (Figure 23). 


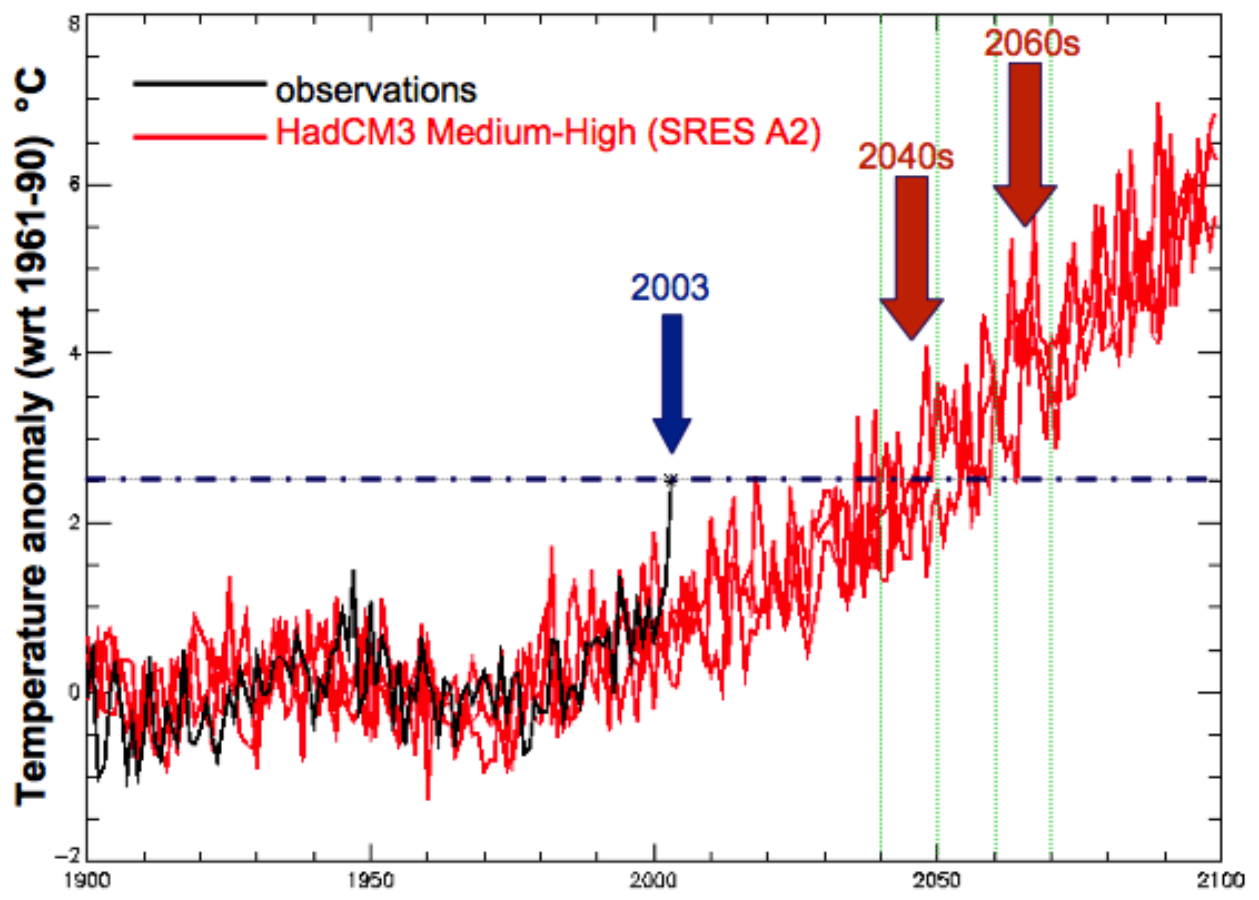

Figure 1 Temperature anomaly of 2003 heat wave in relation to a Medium-High emission trend (Met Office, Crown copyright)

In a future characterised by significantly warmer summer temperatures and an increase in extreme climatic events (Jenkins et al., 2010; Wilby, 2003) active cooling may become necessary to maintain thermal comfort and even to safeguard life (Ostro et al., 2010). The use of domestic air conditioning in the UK is estimated to be rising by $8 \%$ per year (Littlefair, 2005), a phenomenon which could result in an additional six million tonnes of $\mathrm{CO}_{2}$ emissions by 2020 (Rodrigues et al., 2013). Unless they are extensively subsidised, the ownership of cooling systems is likely to reflect socioeconomic inequalities. O'Neill et al (2005) noted that the prevalence of central air-conditioning amongst black households, in four US cities, was less than half that of white households; resulting in greater vulnerability to heat related mortality. Ownership of an air conditioning system does not guarantee immunity from heat related health affects however, since major power blackouts have historically occurred during periods of high heat stress (Ostro et al., 2010). In light of these risks the UK Health Protection Agency have suggested that "Passive cooling options (building orientation, shading, thermal insulation, choice of construction materials, etc.) implemented at the design stage of urban developments may be equally effective as active cooling in reducing the health burden of heat and would be environmentally sustainable options" (Vardoulakis and Heaviside, 2012, p47).

The precise point at which overheating occurs and active cooling is required is central to the assessment of risk, and yet there is no precise or accepted definition of overheating in the UK (NHBC, 2012a, p7). To date much of the building performance literature has been concerned with 
the contiguous issue of thermal comfort; whilst the thresholds at which overheating contributes to elevated health risks have been largely ignored. How thermal comfort and overheating risks are defined will strongly influence the outcome of any overheating investigation and these issues are addressed in the Methodology (Section 4.2). The question of whether the Passivhaus concept can delay the onset of overheating and is inherently less vulnerable to heat related risks (in comparison to a conventional dwelling) is highly relevant to adaptation planning, as well as wider mitigation strategies. Faced with a contiguous increase in both economic and social risk factors, including derated electricity supply margins (DECC, 2011; Ofgem, 2012) and an aging population (ONS, 2012); this question is likely to become increasingly relevant.

\subsection{Thermal Comfort and Heat Related Impacts on Human Health}

From the perspective of evaluating thermal comfort in relation to overheating, an overheating metric and comfort range are typically defined. The two most widely adopted thermal comfort models are the Heat Balance model, found in EN 7730 (2006) as developed by Fanger (1970), and the Adaptive model, found in ASHRAE 55 (2004) and EN 15251 (2007) as presented in the work of de Dear et al (1997), Nicol et al (1999) and Humphreys and Nicol (2002). Berglund (1978) provides an overview of some of the main mathematical models used for predicting thermal comfort.

From a practical perspective Nicol et al $(2009$, p355) acknowledge that where, "the adaptive criteria is determined by both the building category and the mean external dry bulb temperature for a number of previous days, then the measurement and ultimate determination of overheating becomes more complex." Many building performance studies have used consistent indices of thermal comfort in preference to running means (Schnieders, 2009; Rodrigues et al., 2013; Coley et al., 2012; Lomas and Giridharan, 2012) although many of these authors also acknowledge that there is likely to be a difference between current and future thermal comfort thresholds. In the UK, CIBSE Guide A (2006) states that (in warm summer conditions) $25^{\circ} \mathrm{C}$ is an acceptable operative temperature (OT) in the living area of dwellings and $23^{\circ} \mathrm{C}$ is acceptable for bedrooms. CIBSE Guide A (2006) defines 'overheating' as occurring when the OT exceeds $28^{\circ} \mathrm{C}$ for more than $1 \%$ of the annual occupied hours in the living areas of (free running) dwellings or when the bedroom OT exceeds $26^{\circ} \mathrm{C}$ for more than $1 \%$ of the annual occupied hours (unless ceiling fans are available). This assessment is based on a warmer than average summer, using a DSY dataset. It should be noted that CIBSE TM 36 recommends a slightly lower limit (of $25^{\circ} \mathrm{C}$ ) should be regarded as the upper limit of acceptability for the temperature of sleeping areas (CIBSE, 2005a) citing evidence from Thomas et al (1998). 
CIBSE Guide A (2006) also offers an adaptive method of assessing the acceptable OT using an exponentially weighted running mean of the daily mean ambient air temperature $\left(T_{r m}\right)$ at a rate of $0.33 \mathrm{~K}$ per $\mathrm{K}$. The upper and lower comfort bounds are $4 \mathrm{~K}$ apart and the prediction is valid in the $\mathrm{T}_{\mathrm{rm}}$ range of $8^{\circ} \mathrm{C}-25^{\circ} \mathrm{C}$. EN 15251 (2007) uses a very similar approach to the CIBSE method (although the standard is applicable for $T_{r m}$ up to $30^{\circ} \mathrm{C}$ ) and defines two categories of thermal comfort. Cat 1 is applicable for spaces inhabited by very sensitive and fragile persons, including the sick, very young and elderly and uses a $4 \mathrm{~K}$ upper and lower comfort range (identical to the CIBSE method). Whilst Cat 2 is applicable to normal levels of expectation and is considered appropriate for new buildings and renovations, spanning a $6 \mathrm{~K}$ comfort range.

In terms of the upper limit of acceptable internal temperature the CIBSE living area thresholds tend to be higher than those given in EN ISO 7730 (2006) where Category A allows a maximum temperature of $25.5^{\circ} \mathrm{C}$, whilst category B allows $26^{\circ} \mathrm{C}$ (at a relative humidity of $60 \%$ ). These comfort categories are further defined in relation to maximum fluctuations in the OT, whereby a Predicted Percentage Dissatisfied (PPD) of $<6 \%$ is required for Category A and $<10 \%$ for Category B. The overheating threshold used in the Passive House Planning Package (PHPP) (Feist et al., 2012) originated from the German DIN 1946-2 (1994) upper limit of $25^{\circ} \mathrm{C}$. Based on this threshold Rouvel (1997) established the criterion for active space cooling as occurring when the $25^{\circ} \mathrm{C}$ limit was exceeded for more than $10 \%$ of the period of annual usage. For a Passivhaus dwelling this is interpreted as being $10 \%$ of the year, since continual occupancy is assumed (Feist et al., 2012). In the context of energy efficient office buildings, post occupancy research by Voss et al. (2005) suggests that the acceptable duration of overheating above $25^{\circ} \mathrm{C}$ should be reduced to $5 \%$ or less. Contrary to Voss et al.'s recommendation however the recent DIN 4108-2 (2013) incorporated a more adaptive approach, defining a series of three limiting temperatures $\left(25,26\right.$ and $\left.27^{\circ} \mathrm{C}\right)$ that cannot be exceeded for more than $10 \%$ of the occupied period depending on the monthly ambient temperature of the region (below $16.5^{\circ} \mathrm{C}$, below $18^{\circ} \mathrm{C}$ and above $18^{\circ} \mathrm{C}$ respectively). Deutscher (2000) argues that this slackening of overheating limits in the German standards is attributable to the fact that the original targets were too difficult to implement in some German regions without necessitating the use of external shading devices.

Irrespective of whether a deterministic or adaptive approach is used, the criteria which currently define 'overheating' in dwellings have largely evolved from occupant studies of thermal comfort; many of which were carried out in offices and commercial buildings. As a result 'overheating' has been defined as occurring at a point, or range, above which occupants experience discomfort. Dengel and Swainson (NHBC, 2012) suggest a counterproposal to this approach is needed, stating 
that by definition the existing approach is not based on occupant health but is grounded in the concept of 'thermal preference'. Dengel and Swainson's view is supported by the World Health Organisation (WHO) guidance for air temperatures in dwellings (WHO, 1987; WHO, 1990) which is aimed at protecting health, particularly that of those vulnerable to extremes of temperature, and not at sensations of satisfaction with the ambient temperature (Ormandy and Ezratty, 2012). WHO research, suggests that there is minimal risk to the health of sedentary people, including the elderly, in dwellings where the ambient temperature is between $18^{\circ} \mathrm{C}-24^{\circ} \mathrm{C}(\mathrm{WHO}, 1990)$. In support of this approach there is a body of evidence which suggests that the elderly may report feeling comfortable at temperatures which are not, in fact, healthy for them (Watts, 1971; Collins and Hoinville, 1980; Ezratty et al., 2009).

In order to evaluate health and safety risks originating from deficiencies in dwellings the UK Government introduced the Housing Health and Safety Rating System (HHSRS) in 2005 (ODPM, 2006). Since the HHSRS replaced The Housing Fitness Standard contained in section 604 of the 1985 Housing Act (as amended by the schedule 9 to the 1989 Local Government and Housing Act) judgements regarding the lack of safety defined under the HHSRS are enforceable under this Act (Wilson, 2008). Accordingly, the health effects of 'excess heat' have a statutory definition in the HHSRS, which states that, "High temperatures can increase cardiovascular strain and trauma, and where the temperatures exceed $25^{\circ} \mathrm{C}$, mortality increases and there is an increase in strokes. Dehydration is a problem primarily for the elderly and the very young" (ODPM, 2006, p60). In a mortality assessment of England \&Wales Armstrong et al. (Armstrong et al., 2010) established a heat threshold, by statistical model fit, broadly occurring at the 93rd percentile of the all-year daily maximum ambient temperature distribution within any given region. Similar research carried out by the UK Health Agency has shown that the daily mean temperature (rather than maximum temperature) can equally be used at the 93rd percentile as a threshold above which an elevated risk of heat related mortality occurs. In the present day case of London this would correspond to a mean ambient temperature of $19.6^{\circ} \mathrm{C}$ (Vardoulakis and Heaviside, 2012). Whilst regional ambient temperature thresholds and air pollution levels are widely used for epidemiological predictions (Vardoulakis and Heaviside, 2012; Greenberg et al., 1983; NRC, 1991; CDC, 1995; Wainwright et al., 1999), the corresponding building OT and Indoor Air Quality (IAQ) risk thresholds are rarely documented.

Research by Bouchama and Knochel (2002) established that it is the heat stress experienced across day and night that determines the risk of heat related mortality. An improved understanding of the 
relationship between OT thresholds and exposure periods in relation to morbidity and mortality data is therefore of critical importance to adaptive building design and heat risk prevention strategies.

Basu and Samet (2002a) proposed that the micro-environmental model, widely used in assessing individual exposure to atmospheric pollutants, (NRC, 1991) could be extended to create a microenvironmental time weighted exposure model for the assessment of heat related exposure. Their initial fieldwork in Baltimore, USA established the validity of this approach; whilst also pointing to the need for larger population studies in multiple geographic regions together with a better understanding of effect modifiers (sex, age, body mass, air conditioning use, and other behavioural adaptations) (Basu and Samet, 2002b).

To date little work has been carried out in the UK context to establish a robust correlation between OT thresholds and morbidity rates in dwellings, although CIBSE Guide A notes that sleep may be impaired above $24^{\circ} \mathrm{C}$ (CIBSE, 2006). Increased sleep fragmentation has been directly linked to poor health and reduced work place productivity (Buysee et al., 2010) as well as directly impairing the ability to recover from daytime heat stress (Kovats and Hajat, 2008). Changes in skin temperature of as little as $1^{\circ} \mathrm{C}$ are known to impair the quality of sleep, notably in the elderly (Aries and Bluyssen, 2009; Raymann et al., 2008). In light of these findings the OT's of bedrooms should play an important role in the assessment of overheating risk.

Heat exposure alone is not the sole parameter governing heat related mortality. Johnson et al (2003) note that excess mortality in England and Wales was significantly higher during the 2003 heat wave than the 1976 heat wave (16\% compared to $10 \%$ ) despite the temperatures being broadly similar; a situation which they postulate may be attributed to an ageing UK population. The fact that the elderly (over 75 years of age) are more vulnerable to heat related mortality has been documented in both the UK (Rooney et al., 1998) and elsewhere (Cassadou et al., 2004; Na et al., 2013). Alongside this Rooney et al (1998) and Stedman (2004) have documented that elevated ground level ozone $\left(\mathrm{O}_{3}\right), \mathrm{PM}_{10}$ (particulate matter $<10 \mu \mathrm{m}$ in diameter) and Nitrogen dioxide $\left(\mathrm{NO}_{2}\right)$ played a contributory role in the localised incidence of mortality during the 1995 and 2003 UK heat waves. Despite the relevance of these findings to the urban context a detailed evaluation of these concomitant factors is beyond the scope of this thesis. 


\section{MeTHODOLOGY}

The research presented here expands on chapter 3 by investigating the likely future performance of UK dwellings built to the Passivhaus standard under a series of future probabilistic climatic scenarios.

In the first stage a DSP was used to model a range of individual interventions in order to understand the general evolution of the Passivhaus and FEES dwellings faced with increasingly severe climate change scenarios. In the second stage of the research a Global Sensitivity Analysis technique was introduced in order to examine which design factors, within the designers influence, have the most pronounced impact on the buildings future performance.

Three different variants of a typical Passivhaus dwelling were modelled in order to account for the influence of thermal mass. An additional control model was used throughout the study in order to show the comparative performance between the Passivhaus concept and a similar dwelling built to comply with the proposed Fabric Energy Efficiency Standard (FEES) (ZCH, 2008).

Although extremes of hot weather are likely to become much more common in the future (Jenkins et al., 2007; Jones et al., 2008), climate models predict that extreme cold weather events are still likely to occur even under 21st century warming scenarios (Kodra et al., 2011). In accordance with this finding, the impacts on both overheating and heating parameters were evaluated; in order to assess whether design interventions that may have influenced one parameter positively, had done so at the expense of another. 


\subsection{Simulation Setup and Parameterization}

\subsubsection{DWELLING- LOCATION AND TYPOLOGY}

A 5 x 5km grid square centred on Islington, UKCP cell reference 5350185 (DEFRA, 2009) was chosen as the context for this study, in order to include some of the additional affects induced by the UHI within an urban location (see Section 4.2.3.1 for more information).
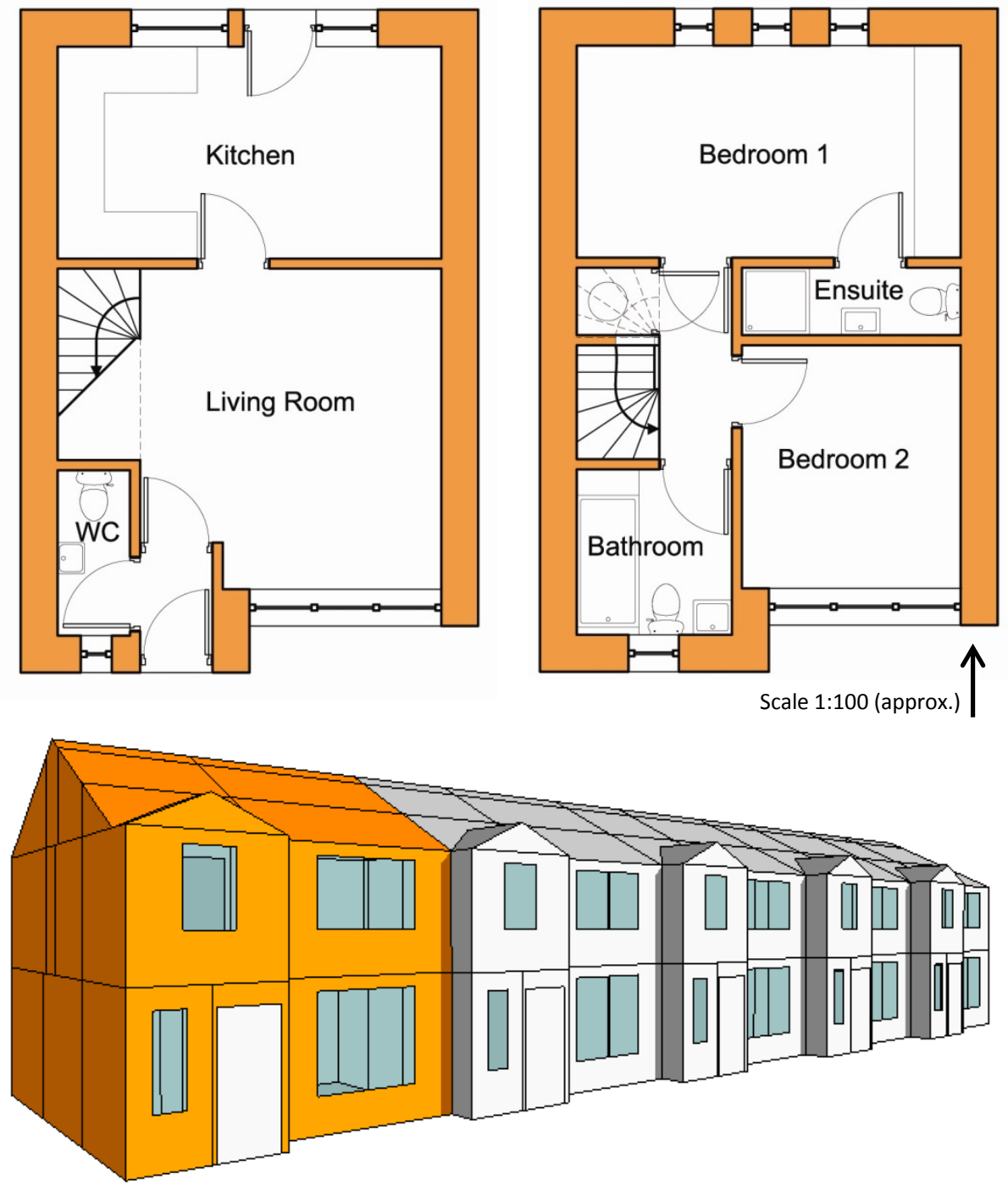

Figure 2 Floor plans and IES model view showing end terrace dwelling (South elevation)

A two bedroom end of terrace dwelling with a gross internal floor area of $70 \mathrm{~m}^{2}$ was used as representative format for this study. A dwelling at the western end of the terrace row (Figure 24) was chosen, consistent with similar studies (Ford et al., 2007; Schnieders, 2009) based on the logic that this unit is most exposed to the influence of solar irradiation during the afternoon when the sun is in the western hemisphere and ambient temperatures peak. 
Dwelling typology has been shown to have a significant effect on both heating demand and overheating risks. In comparison to detached dwellings, compact dwelling formats (with reduced external surface areas) are likely to have lower transmission heat losses in winter but conversely may be prone to greater summer overheating risks as a result of reduced external heat exchange surfaces and fewer ventilation openings. Research investigating future overheating in the UK Housing stock by Gupta and Gregg (2012) demonstrated that purpose built flats and mid-terraced houses were at significantly greater risk of overheating in future climatic scenarios than semidetached or detached dwellings. Porritt et al. (2012) also showed that dwelling orientation plays a decisive role in determining the magnitude of overheating risks, with end of terrace dwellings having less risk of overheating than mid-terrace dwellings when facing West but conversely greater risk of overheating for North, South and East orientations.

The dwellings were orientated to face south, as this is consistent with optimal Passivhaus design in the Northern hemisphere, since it allows the greatest utilisation of passive solar gains during the winter heating season (Feist et al., 2012). The dwellings were assumed to be positioned on a horizontal plane without topographical shading (Figure 24).

Whilst this arrangement is considered to be optimal from a passive solar design perspective, it is acknowledged that a large number of site specific constraints (including shading obstructions, density requirements and access issues) are likely to have a significant influence on the performance of dwellings built in an urban context. For these reasons the findings of this study should be viewed as a comparative analysis of a series of theoretical future scenarios rather than a context specific deterministic study.

\subsubsection{SIMULATION SOFTWARE}

The IES-ve (2012) v6.4 Apache software was used for the dynamic simulations in this study. Apache was developed in the early 1990's and is a widely used DSP both in the UK and internationally. Apache has an extensive validation history which was documented using the CIBSE Applications Manual AM 11 (1998) Appendix B protocol (CIBSE, 1998) by McLean in 2006 (IES, 2009). The software performed well in independent Building Energy Simulation Test (BESTEST) (Judkoff and Neymark, 1995) benchmarking assessment carried out by the BRE (IES, 2009) and has been subject to extensive Empirical testing by Lomas et al. (1994) and Gough and Rees (2004). Apache uses a finite difference discretization scheme known as 'hopscotch' whereby explicit and implicit time stepping is applied to alternate nodes in the construction; this approach is thought to provide both accurate and efficient computation (Struck, 2012). 


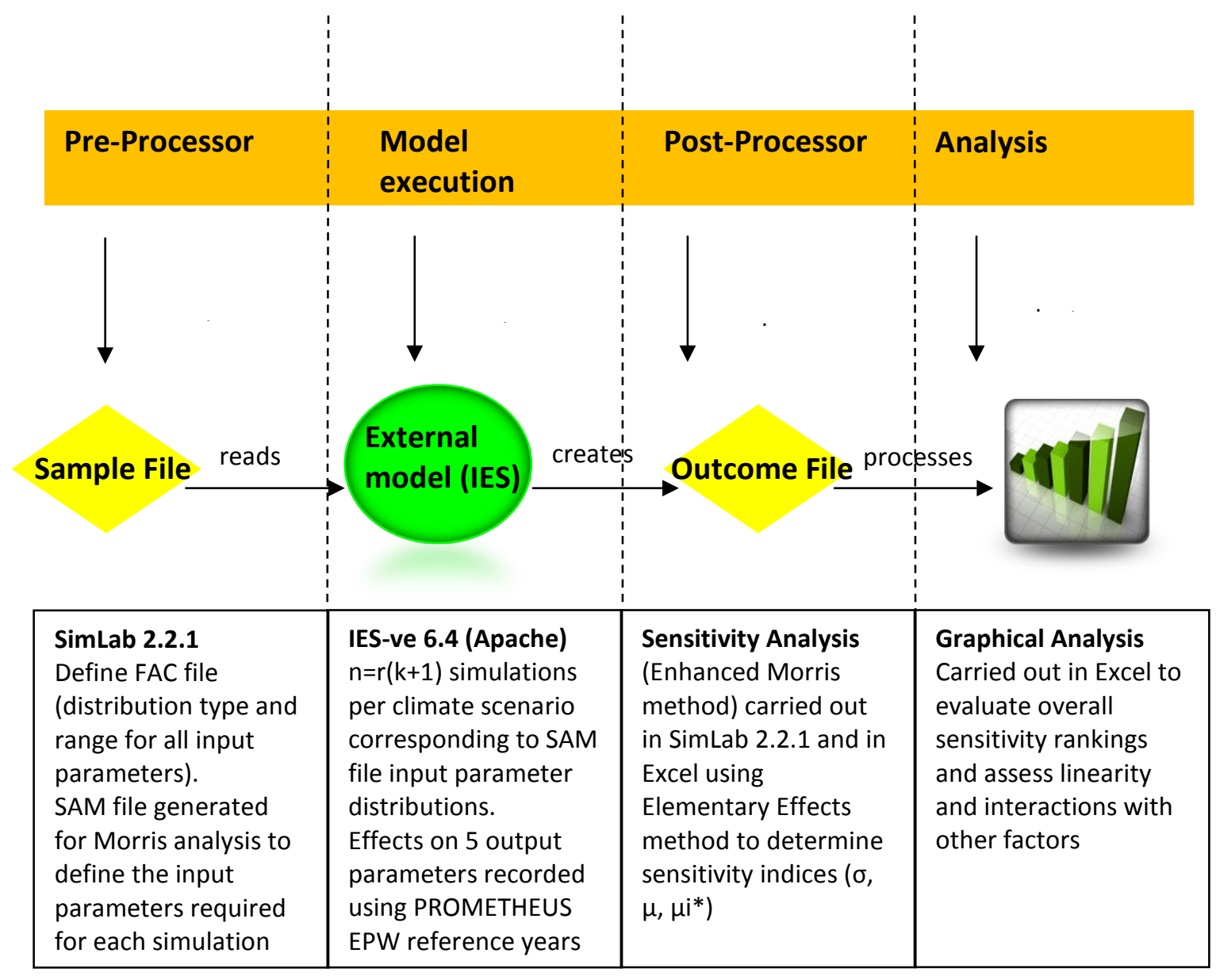

Figure 3 Simulation and analysis procedure

\subsubsection{DWelling Specification- Thermal Characteristics, Glazing Ratios, Ventilation}

Whilst a number of previous studies have addressed the role of thermal mass in relation to overheating risks in UK dwellings (ARUP, 2005; EST, 2005a; EST, 2005b; Hacker et al, 2008; Orme and Palmer, 2003; Rodrigues et al., 2013; Rodrigues, 2009; Rodrigues and Gillot, 2011), none of these studies has investigated the influence of thermal mass in the context of Passivhaus dwellings. In order to evaluate the role thermal mass might play in Passivhaus dwellings in a future UK climatic context three different construction types (light, medium and heavyweight) were selected as representative of a range of UK Passivhaus constructions (Table 5). In order to provide a control study, for comparative analysis, a naturally ventilated FEES compliant dwelling was modelled in a traditional heavyweight construction format (Table 5), in accordance with the FEES specification $(\mathrm{ZCH}, 2009)$. The effects of linear thermal bridging were incorporated into the FEES DSP model by adding a y value adjustment factor of $0.05 \mathrm{~W} /\left(\mathrm{m}^{2} \mathrm{~K}\right)$ to the opaque $U$ values $(\mathrm{ZCH}, 2009)$. 
Internal volumes, glazing ratios, external emissivity and solar absorptance coefficients remained consistent between all four dwelling models. In addition to the above criteria, the Passivhaus dwellings were modelled using a common ground floor construction (pre-insulated raft slab) as well as identical: fabric U-values, glazed U-values, g-values, infiltration and ventilation rates (Table 5). All Passivhaus dwellings were assumed to be 'thermally bridge free' in keeping with the criteria set out in the Passive House Planning Package (Feist et al., 2012, p109). 
Table 1 Principal performance characteristics of 4 dwelling types ( 3 complying with the Passivhaus standard and 1 with the FEES Standard)

\begin{tabular}{|c|c|c|c|c|}
\hline & FEES HEAVY & PH HEAVy & PH MEDIUM & PH LIGHT \\
\hline Construction type & $\begin{array}{l}\text { Cavity wall } \\
\text { wet plastered }\end{array}$ & $\begin{array}{l}\text { Full-fill cavity } \\
\text { wet plastered }\end{array}$ & $\begin{array}{l}\text { TGI stud } \\
\text { double lined }\end{array}$ & $\begin{array}{l}\text { SIPS panel dry } \\
\text { lined }\end{array}$ \\
\hline U- value walls $\left[\mathrm{W} /\left(\mathrm{m}^{2} \mathrm{~K}\right)\right]$ & $0.23^{\dagger}$ & 0.14 & 0.14 & 0.14 \\
\hline U- value roof $\left[\mathrm{W} /\left(\mathrm{m}^{2} \mathrm{~K}\right)\right]$ & $0.18^{\dagger}$ & 0.10 & 0.10 & 0.10 \\
\hline U- value ground floor $\left[\mathrm{W} /\left(\mathrm{m}^{2} \mathrm{~K}\right)\right]$ & $0.23^{\dagger}$ & 0.10 & 0.10 & 0.10 \\
\hline Thickness walls [m] & 0.3569 & 0.4860 & 0.3222 & 0.2383 \\
\hline Thickness roof [m] & 0.2545 & 0.4262 & 0.4823 & 0.3882 \\
\hline Thickness ground floor [m] & 0.224 & 0.511 & 0.511 & 0.511 \\
\hline Total heat capacity walls $\left[\mathrm{kJ} /\left(\mathrm{m}^{2} \mathrm{~K}\right)\right]$ & 293.4 & 341.6 & 95.3 & 65.5 \\
\hline Uninsulated heat capacity walls & 153.6 & 154.7 & 48.2 & 15.8 \\
\hline$\left[\mathrm{kJ} /\left(\mathrm{m}^{2} \mathrm{~K}\right)\right]$ & & & & \\
\hline Total heat capacity roof $\left[\mathrm{kJ} /\left(\mathrm{m}^{2} \mathrm{~K}\right)\right]$ & 60.4 & 100.7 & 92.7 & 72.8 \\
\hline Uninsulated heat capacity roof & 15.8 & 15.8 & 15.8 & 15.8 \\
\hline$\left[\mathrm{kJ} /\left(\mathrm{m}^{2} \mathrm{~K}\right)\right]$ & & & & \\
\hline $\begin{array}{l}\text { Total heat capacity ground floor } \\
{\left[\mathrm{kJ} /\left(\mathrm{m}^{2} \mathrm{~K}\right)\right]}\end{array}$ & 240.84 & 511.1 & 511.1 & 511.1 \\
\hline $\begin{array}{l}\text { Uninsulated heat capacity ground } \\
\text { floor }\left[\mathrm{kJ} /\left(\mathrm{m}^{2} \mathrm{~K}\right)\right]\end{array}$ & 37.2 & 501.2 & 501.2 & 501.2 \\
\hline
\end{tabular}




\begin{tabular}{|c|c|c|c|c|}
\hline $\begin{array}{l}\text { Total heat capacity internal walls } \\
{\left[\mathrm{kJ} /\left(\mathrm{m}^{2} \mathrm{~K}\right)\right]^{*}}\end{array}$ & 157.2 & 157.2 & 81.7 & 31.7 \\
\hline $\begin{array}{l}\text { Total heat capacity internal floor } \\
{\left[\mathrm{kJ} /\left(\mathrm{m}^{2} \mathrm{~K}\right)\right]}\end{array}$ & 185.84 & 185.84 & 91.43 & 31.4 \\
\hline $\mathrm{U}_{\mathrm{w}}$ value whole window $\left[\mathrm{W} /\left(\mathrm{m}^{2} \mathrm{~K}\right)\right]$ & 1.4 & 0.7942 & 0.7942 & 0.7942 \\
\hline $\mathrm{U}_{\mathrm{g}}$ value glass $\left[\mathrm{W} /\left(\mathrm{m}^{2} \mathrm{~K}\right)\right]$ & 1.4053 & 0.8017 & 0.8017 & 0.8017 \\
\hline g value [EN 410] & 0.721 & 0.618 & 0.618 & 0.618 \\
\hline Infiltration [effective ac/h] & 0.152 & 0.035 & 0.035 & 0.035 \\
\hline Efficiency of MVHR Unit [ - ] & - & $85 \%$ & $85 \%$ & $85 \%$ \\
\hline Mechanical supply air flow rate & - & $30 \mathrm{~m}^{3} / \mathrm{pp} . \mathrm{h}$ & $30 \mathrm{~m}^{3} / \mathrm{pp} . \mathrm{h}$ & $30 \mathrm{~m}^{3} / \mathrm{pp} . \mathrm{h}$ \\
\hline Natural vent strategy & see profile & see profile & see profile & see profile \\
\hline Psi value or $y$-value incorporated & Y value incl. & bridge free & bridge free & bridge free \\
\hline Ground coupling integrated & via EPW & via EPW & via EPW & via EPW \\
\hline Cooling coil used & see scenario & see scenario & see scenario & see scenario \\
\hline Humidity control for cooling & see scenario & see scenario & see scenario & see scenario \\
\hline
\end{tabular}

According to CIBSE Guide $\mathrm{B}$ in the UK a $\mathrm{CO}_{2}$ level of $800-1000$ ppm (equating to a fresh air ventilation rate of approximately $8 \mathrm{~s}^{-1}$ per person) is widely used as an indication that the ventilation rate in a building is adequate (CIBSE, 2005b, p15). $\mathrm{CO}_{2}$ is often used as a proxy indicator of Indoor Air Quality (IAQ) in general (Taylor and Morgan, 2011) and concentrations above 5000 ppm $\mathrm{CO}_{2}$, for more than 8 hours, are considered to represent the upper limit of acceptability in the UK (CIBSE, 2005b). 
In both the FEES and Passivhaus dwellings, $\mathrm{CO}_{2}$ concentrations were used as a proxy indicator of IAQ, with the goal of maintaining an upper threshold $\leq 1000$ ppm above ambient levels. Supply air ventilation in the Passivhaus dwellings was provided via Mechanical Ventilation with Heat Recovery (MVHR) and a summer heat exchanger bypass system was modelled whenever the outside temperature exceeded $20^{\circ} \mathrm{C}$. In contrast the FEES control dwelling utilised natural cross ventilation via ramped window opening profiles to maintain the 'supply air quality' (Table 6). In order to control overheating risks, an identical purge ventilation strategy was used in both the FEES and Passivhaus dwellings in accordance with the 'purge ventilation' profile strategy (Table 6). Maximum window opening angles were limited to 10 degrees in all dwellings in keeping with the use of window restrictors. Such devices are a standard safety feature in new build social housing in the UK in accordance with guidance from the Royal Society for the Prevention of Accidents (RoSPA, 2005).

Table 2 Ventilation profiles according to dwelling type

\begin{tabular}{|c|c|c|}
\hline DWELLING TYPE & VENTILATION REQUIREMENT & VENTILATION PROFILE \\
\hline FEES model & 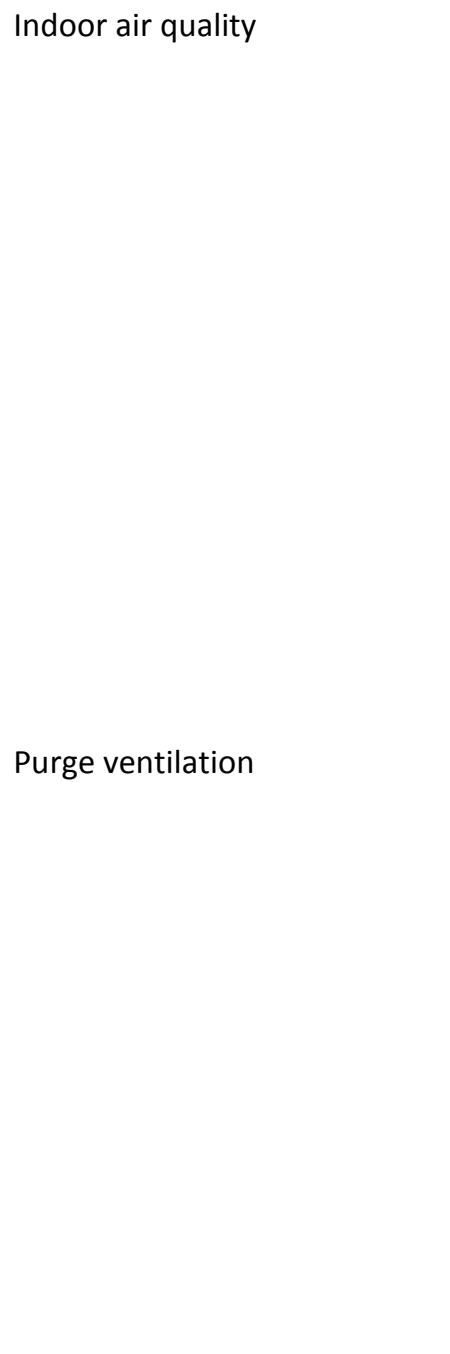 & $\begin{array}{l}\text { Windows ramp open for ventilation when } \mathrm{CO}_{2}>1000 \mathrm{ppm} \\
\text { with window opening threshold limited to } 10 \% \text {. If } \mathrm{CO}_{2} \\
>2000 \mathrm{ppm} \text { then the opening threshold is increased to } 50 \% \\
\text { to maintain air quality. Windows are closed when } \mathrm{CO}_{2} \\
\leq 1000 \mathrm{ppm} \text { or outside air temperature } \leq 5^{\circ} \mathrm{C} \text { or wind speed } \\
\text { is }>7 \mathrm{~ms}^{-1} \\
\text { When the internal temperature }>22^{\circ} \mathrm{C} \text { and the internal } \\
\text { temperature is }>\text { external temperature the windows open } \\
\text { progressively (using ramped profile) with maximum } \\
\text { opening of all windows when the internal temperature } \\
\text { reaches } 26^{\circ} \mathrm{C} \text {. Window opening restrictors are assumed to } \\
\text { limit the maximum opening angle to } 10^{\circ} \\
\text { efficiency at a constant flow rate of } 30 \mathrm{~m}^{3} \text { per person per } \\
\text { hour. If the outside temperature is }>20^{\circ} \mathrm{C} \text { the heat } \\
\text { exchanger is bypassed and the same flow rate is supplied }\end{array}$ \\
\hline
\end{tabular}




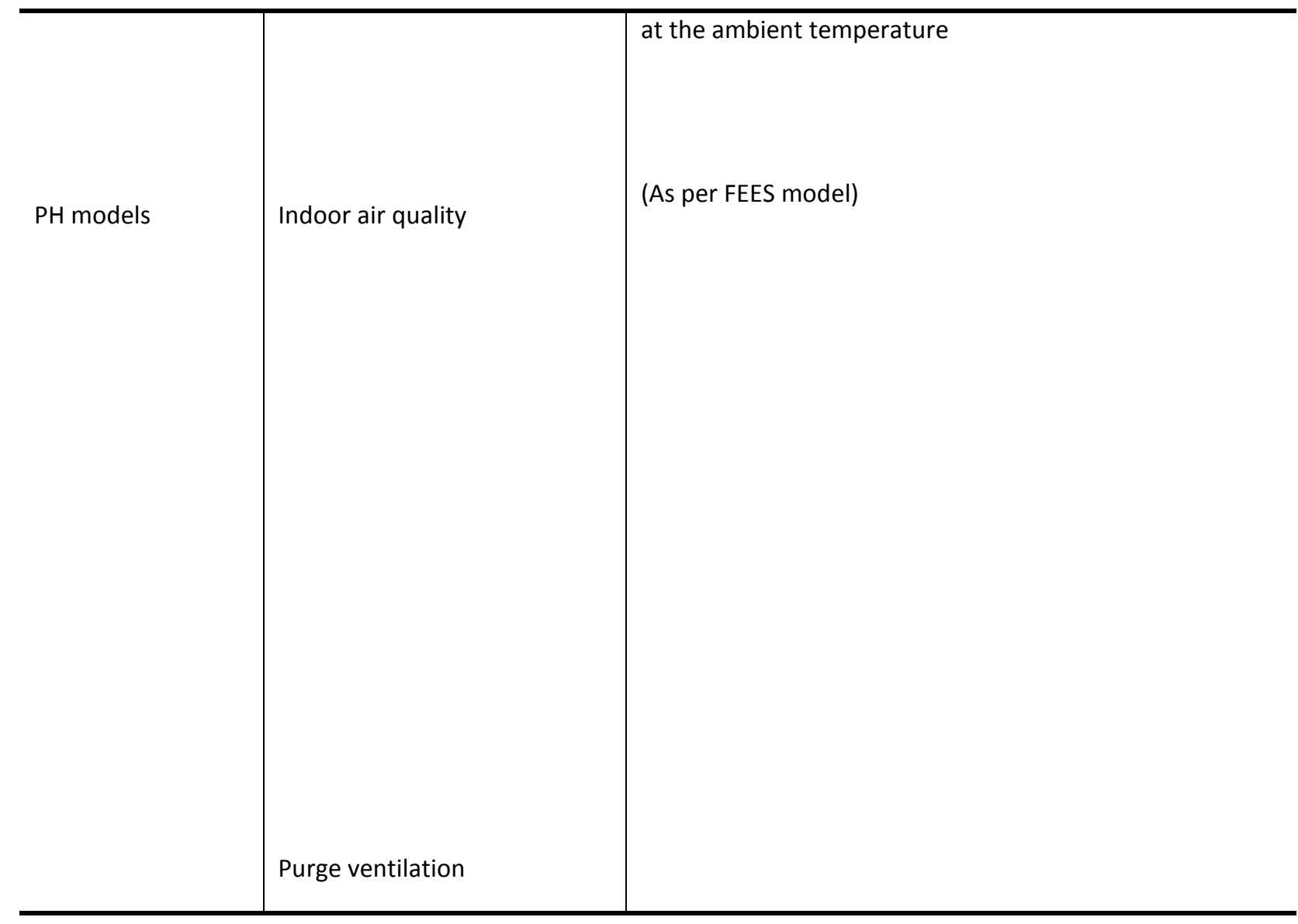

In order to model the ventilation profile of the FEES and Passivhaus dwellings in accordance with the above guidance two independent window opening profiles were used. In the FEES model, the first ventilation profile was defined by $\mathrm{CO}_{2}$ concentration and the second by the requirement to 'purge' excess heat. In the Passivhaus model IAQ is maintained by mechanical ventilation via the MVHR unit and additional 'purge' ventilation is modelled as a cooling strategy using the same (restricted) window opening profile as for the FEES model (Table 6).

\subsection{INTERNAL GAINS AND OCCUPANCY PATTERNS}

The occupancy patterns and internal gains profiles used were common amongst all four dwellings.

\subsubsection{INTERNAL GAINS}

The Passive House Planning Package (Feist et al., 2012) uses a default assumption of $2.1 \mathrm{~W} / \mathrm{m}^{2}$ with respect to the effective residential internal heat gains (IHG's). This figure is then rounded upwards to $2.6 \mathrm{~W} / \mathrm{m}^{2}$ (as a safety margin) in the PHPP model for the purpose of assessing summer overheating risk. The derivation of these figures is based upon assessments carried out in German Passivhaus dwellings using a default occupant density of $35 \mathrm{~m}^{2}$ per person and actual appliance schedules (Feist, 1994). The 'effective' IHG figures used in PHPP account for both the internal heat 
gains (including occupants) as well as the internal heat losses (e.g. cold water entering cisterns, evaporation ) (Feist et al., 2012). A detailed breakdown of this calculation procedure can be found in Schnieders (2009, p75).

For the purpose of this study the standard residential IHG figures of $2.1 \mathrm{~W} / \mathrm{m}^{2}$ used in PHPP (2012) was adjusted using the PHPP 'Internal Gains' worksheet (see Appendix A1) in order to reflect the higher UK social housing occupant densities (and smaller TFA). Using this approach the appliance and services IHG's based on 3 occupants (but excluding the occupant gains) are: $180 \mathrm{~W}$ (total) - 132 $\mathrm{W}$ (occupant gains) $=48 \mathrm{~W}$ (appliance and services gains). Scaling this to the $70 \mathrm{~m}^{2}$ treated floor area the resulting (appliance and services) specific internal gains are $0.69 \mathrm{~W} / \mathrm{m}^{2}$. Using occupant gains from CIBSE Guide A (CIBSE, 2007) based on three occupants (assuming two adults and a mature child) the total internal sensible heat gains are: $48 \mathrm{~W}+\left(3^{*} 70 \mathrm{~W}\right)=258 \mathrm{~W}$. Adjusting this to the $70 \mathrm{~m}^{2}$ treated floor area the total specific internal gains are $3.69 \mathrm{~W} / \mathrm{m}^{2}$ (when the dwelling is fully occupied).

In order to assess the sensitivity of the key outputs relative to the internal gains assumptions, in the second part of this study, the influence of low and high IHG figures were assessed. Based on the assumption that the figures currently specified in the PHPP software (Feist et al., 2012) are likely to reflect the use of very energy efficient appliances and moderate electricity consumption profiles the above figure was taken as a the basis for the 'low IHG' profile. Assuming that IHG's could be elevated by a factor of up to 3, in some households (Henderson, 2009; Schnieders, 2009) the 'high IHG' appliance and services gains were estimated as $3 \times 48 \mathrm{~W}$, thus the specific (appliance and services gains) would be $144 \mathrm{~W} / 70 \mathrm{~m}^{2}=2.06 \mathrm{~W} / \mathrm{m}^{2}$. Using occupant gains from CIBSE Guide $A(2006)$ based on three occupants (assuming two adults and a mature child) the total internal sensible heat gains are: $144 \mathrm{~W}+\left(3^{*} 70 \mathrm{~W}\right)=354 \mathrm{~W}$. Scaling this to the $70 \mathrm{~m}^{2}$ treated floor area the total 'high' (nonoccupant related) internal gains are $5.05 \mathrm{~W} / \mathrm{m}^{2}$ (when the dwelling is fully occupied).

\subsubsection{0cCupant Density and PATterns}

In order to create a realistic occupancy profiles for the purpose of this study occupant numbers were modelled as a whole number. A larger than average household size based on 3 occupants was chosen in order to err on the side of higher occupant density and internal gains. Occupancy schedules were created to reflect UK household survey statistics (DECC, 2012b). Occupant gains were then assigned to the IES model based on sub-hourly activity data recorded in the UK Time Use Survey (ONS, 2005) with occupant gains data according to activity from CIBSE Guide A (CIBSE, 2007). The weekly occupancy profiles were assigned to the model based on sub-hourly activity profiles 
created for the 3 occupants. Weekly profiles were created for a 'working adult', a non- working 'houseparent' and a 'student'. Maximum occupancy was assumed at weekends in order to test the influence of higher than average internal heat gains during these periods.

\subsection{Future Climate Data and Scenarios}

\subsubsection{Future Climate Data and the Urban Context}

The UKCP09 grid location 5350185 (DEFRA. 2009), centred on London Islington, has been selected as the reference location for this study. London's urban context is known to create a pronounced micro climate: with one of the consequences being that temperatures are at times significantly higher than surrounding rural areas. Research by Graves et al. (2001) demonstrated that the nocturnal ambient temperature peak for Westminster, London, have occasionally exceeded 7K during the summer months. The temperature difference between an urban area and its rural surroundings is commonly referred to as the urban heat island (UHI) effect, and is typically most pronounced at night (Kershaw et al., 2010). This localised phenomenon results primarily from the heat generated by human energy production (HEP) being retained in an area of high thermal mass e much of which also has a relatively low albedo, or surface reflectivity (Graves et al., 2001; DEFRA, 2013). One of the main challenges for overheating risk prevention in urban dwellings occurs as a result of the magnitude and the timing of the peak intensity of the UHI, which in inner London locations can occur between 11 pm and 8 am (DEFRA, 2012; Wilby, 2003). The resultant dampening of the diurnal temperature range has implications for the cooling of naturally ventilated buildings, as it compromises the effectiveness of strategies using night-time 'purge' ventilation to cool thermal mass. For this reason it is important that any synthesised or predictive weather data used in an urban modelling context accurately reflects the localised influence of the urban micro climate.

Some caution is necessary with respect to the future climatic changes predicted by the UKCPO9 scenarios in dense urban areas, since an explicit representation of urban areas was not included in the HadRM3 model (Kershaw et al., 2010). In a large urban conurbation such as Greater London the effects of the existing UHI are captured in the UKCP Weather Generator (WG) model by virtue of the fact that a number of the climate stations used for the interpolation process are situated within the UHI (Kendon, 2012). At the $25 \mathrm{~km}^{2}$ resolution of the HadRM3 model the largest urban areas can be seen to exert some influence on the local simulated climate (McCarthy et al., 2009). It follows therefore, that if the UHI effect does not change significantly in the future, it is reasonable to add the UKCP09 climate change projections to the observed baseline $\left(5 \mathrm{~km}^{2}\right)$ urban climate in order to generate future urban climatic predictions at this scale (Kendon, 2012). Conversely if future changes 
occur in the amount of energy dissipated in cities (e.g. cooling systems become widespread), or if the density of a city changes then these factors could alter the current UHI effect, and projecting future climates in cities will then require additional techniques to be deployed (Kershaw et al., 2010).

In relation to the temporal evolution of the $\mathrm{UHI}$, comparative temperature measurements taken at an inner city location (St. James Park) and a suburban site in Surrey suggest that London's nocturnal UHI has intensified by approximately $0.5 \mathrm{C}$ on since the 1960s (Kendon, 2012), partly as a consequence of increased HEP, denser urbanisation, and the changing frequency of weather patterns. Since the $5 \mathrm{~km}^{2}$ baseline data is based on measured data collated over the 1961/1990 period it is likely that only a relatively small component of these evolutionary changes are missing from the UKCP09 projections (McLeod et al., 2012). The main limitation of the UKCP09 WG projections is that the current model does not fully incorporate all of the highly localised effects of the UHI (Kershaw et al., 2010); significant discrepancies may therefore be anticipated when attempting to predict the performance of buildings at a higher resolution than the current $5 \mathrm{~km}^{2}$ grid allows.

Generating an improved understanding of the future evolution of localised UHI's is a complex and important area for building simulation, where significant further research is needed. For more information on the implications of the London UHI for micro regional assessments of building performance, refer to McLeod et al. (2012) Kershaw et al. (2010) Graves et al. (2001), Watkins et al. (2002) and Wilby (2003).

\subsubsection{AsSESSING RISK- EMISSIONS SCENARIOS AND PROBABILITY}

In order to represent both a mean weather year and a warmer than average (one in ten) year both the $50^{\text {th }}$ and $90^{\text {th }}$ percentile Test Reference Year (TRY) datasets were used to assess future climate change impacts. An alternative procedure, to assess warmer than average future weather years, would be to use Design Summer Years (DSYs) - which are also available from the PROMETHEUS database (Eames et al., 2012; Coley et al., 2012). DSY years are intended to represent the third warmest summer (April-September period) in a twenty year period (Levermore and Parkinson, 2006), however the statistical basis under-pinning their selection is considered to be unreliable. Coley et al. (2012) remark that some of the current DSY's, generated from observed data, are in fact cooler than the TRY datasets for some UK cities.

The WG is capable of generating probabilistic weather files for each future decade from 2020 to 2080 sampled from any percentile of the Probability Density Function (PDF). Whilst the underlying 
Met Office grid data for the period 1961- 1990 is used to create a control dataset, reflecting the historical 1970's baseline (Met Office, 2011). In studying the temporal evolution of climate change the UKCP09 data leaves a large gap (50 years) between the historic control period (1970's) and the near future (2020's). In order to fill this gap and to model current day climatic conditions the CIBSE London 2005 TRY and DSY climate files were used in this study.

\subsection{Performance Criteria - Thermal Comfort and Overheating Thresholds}

In this study the frequency of living area operative temperatures $>25^{\circ} \mathrm{C}\left(\mathrm{OT}_{25}\right)$ was assessed in keeping with the Passivhaus assessment criterion (Feist et al., 2012), WHO guidance (WHO, 1990) and the HHSRS assessment criteria (ODPM, 2006). In addition a higher threshold was used to assess the frequency of living area operative temperatures $>28^{\circ} \mathrm{C}\left(\mathrm{OT}_{28}\right)$ in accordance with CIBSE Guide $A$ (2007) and CIBSE TM36 (2005). The absolute maximum internal operative temperature (OT $\max$ ) was also recorded (as an indicator of heat related mortality risk) for comparative purposes (Basu and Samet, 2002b; Hajat et al., 2002; Hales et al., 2000; Larsen 1990; Nakai et al., 1999). Since the impacts of warmer operative temperatures in bedrooms requires special consideration, the frequency of bedroom operative temperatures $>26^{\circ} \mathrm{C}$ (BedOT 26 ) during occupied hours (11pm-7am) was assessed in relation to the CIBSE Guide A threshold (2007) and the Predicted Percentage Dissatisfied (PPD) (EN ISO 7730, 2006). Bedroom overheating risks are considered to be particularly important in relation to performance criteria in an urban context due to the timing of the peak intensity of the UHI (as discussed in section 4.2.3.1)

\subsection{SENSITIVITY ANALYSIS}

For reasons of computational economy, most building simulation studies are based on a limited number of deterministic scenarios. As a result, in some cases, the dependence of performance outcomes upon key input parameters and their possible interactions may remain unknown. Sensitivity Analysis techniques enable designers to understand which input factors have the most important influence on outputs, and the use of Sensitivity Analysis has been extensively documented in relation to building simulation (Burhenne et al., 2010; Hopfe and Hensen, 2011; Struck 2012; Garcia Sanchez et al., 2012).

\subsection{1elementary Effects Method}

Morris (1991) developed an efficient screening method for determining which input factors have important direct and indirect effects on an output. Morris' method, also known as the Elementary 
Effects (EE) method, is considered to be a Global Sensitivity Analysis (GSA) technique because it samples the entire space over which the input factors may vary. The method uses an individually randomised one- factor at- a-time (OAT) sampling method, to assess which parameters are: i) noninfluential or negligible ii) linearly influential iii) non-linearly influential (or influential by interaction with other parameters) (Campolongo et al., 2007; Saltelli et al., 2004). The Latin hypercube (LH) sampling technique (McKay et al., 1979) is often used to create the starting points for the OAT sampling. LH divides each factor into $r$ stratified intervals of equal probability, which are then sampled OAT.

Morris' method has undergone further enhancement by Campolongo et al. (2005) and has been validated against qualitative variance based methods (such as the method of Sobol') by a number of researchers (Wang et al., 2006; Campolongo et al., 2007; Donatelli et al., 2009; Confalonieri et al., 2010). One of the main advantages of the Morris method is the low sample size required to evaluate the effect of each factor. The number of model executions required is $r(k+1)$, where $k$ is the number of factors and $r$ is a predetermined number of sampling intervals. In comparison the widely used Sobol' method requires in the order of $500(k+2)$ evaluations (Campolongo et al., 2007). As a result the enhanced Morris method is well suited to studies which have either a large number of input factors or require expensive computation.

Mathematically the building simulation model can be represented as the function $y(x)$ where $y$ is the output variable of interest and $x$ is a row vector composed of real input variables with $k$ input coordinates $\left(x_{1}, x_{2}, x_{3}, \ldots x_{k}\right)$. Each input variable is defined within a given interval $\left(x_{\min }-x_{\max }\right)$ and the input variables are then scaled into dimensionless variables in the interval $[0,1]$, such that $x_{i}^{\prime}$ $=\left(x_{i}-x_{\min } / x_{\max }-x_{\min }\right)$. The region of interest $(\Omega)$ is defined by the domain of the vector $x$ which can be visualised as a $k$ dimensional unit hypercube $\left(H^{k}\right)$ which is composed of $p$ discrete grid levels.

A number of different sampling strategies have been proposed in order to optimize the scanning of the input space (Garcia Sanchez et al., 2012; Campolongo et al., 2007; Saltelli et al., 2008). The sampling strategy results in the construction of $r$ different random simulation trajectories in $\Omega$, where each trajectory corresponds to $(k+1)$ model executions and each sampling point differs from the proceeding point by a single, randomly permutated, coordinate. Thus for a given trajectory $r$ each input parameter $(k)$ changes only once in accordance with a pre-defined step size $\Delta_{i}$. The relationship between the number of grid levels $(p)$ in the hypercube and the step size between coordinates $(\Delta)$ is critical to ensuring an equal probability of sampling at every level of the input space. For this reason Morris (1991) recommended that $p$ be an even number, and that 
$\Delta=p /\left[2\left(p_{i}-1\right)\right]$ in order that each sampling point $x_{i}$ has an equal probability of taking on values from $\{0,1 /(p-1), 2 /(p-2), \ldots, 1\}$.

If $x^{(l)}$ and $x^{(l+1)}$ are two sampling points in the $n$th trajectory which differ only in their $i$ th component then the elementary effect $\left(E E_{i}^{n}\right)$ of the $n$th trajectory associated with input factor $i$ is:

$E E_{i}^{n}\left(x^{(l)}\right)=\frac{\left[y\left(x^{(l+1)}\right)-y\left(x^{(l)}\right)\right]}{\Delta_{i}}$

Where the $i$ th component of $x^{(l)}$ is increased by $\Delta_{i}$ (Eq.17), and conversely:

$E E_{i}^{n}\left(x^{(l+1)}\right)=\frac{\left[y\left(x^{(l)}\right)-y\left(x^{(l+1)}\right)\right]}{\Delta_{i}}$

Where the $i$ th component of $x^{(l)}$ is decreased by $\Delta_{i}$ (Eq.18)

The function $y(x)$ is re-evaluated at every point in the trajectory by running the simulation model, thereby allowing a coefficient of output variation (or EE) to be computed for each input factor $i$, for $i$ $=1, \ldots, k$. Once the EEs for each input factor have been determined, sensitivity statistics can be computed relative to the output distributions: The mean $\mu$ provides an indication of the overall importance of an input factor, whilst $\sigma$ (an estimate of the standard deviation) indicates the magnitude of the higher order effects of a factor (i.e. those which are non-linear and/or result from interactions with other factors).

$\mu_{i}=\frac{1}{r} \sum_{n=1}^{r} E E_{i}^{n}$

$\sigma_{i}=\sqrt{\frac{1}{(r-1)} \sum_{n=1}^{r}\left(E E_{i}^{n}-\mu_{i}\right)^{2}}$

Since EEs with a negative sign can occur where input variables have a non-monotonic response on the output (or are involved in interaction effects) Campolongo et al (2007) proposed the use of the mean of the absolute EEs ( $\left.\mu_{i}^{*}\right)$ (Eq.21) as a more reliable indicator of the overall influence of the factor on the output.

$\mu_{i}^{*}=\frac{1}{r} \sum_{n=1}^{r}\left|E E_{i}^{n}\right|$ 
Campolongo et al. (2007) demonstrated that $\mu^{*}$ is a good proxy of the total sensitivity index $\left(\mathrm{S}_{\mathrm{T}}\right)$. According to Saltelli et al. (2008) the use $\mu^{*}$ also solves the problem of type II errors (failure to identify a factor which has considerable influence on the model). In order to evaluate the respective influence of these sensitivity measures Morris (1991) recommended using a graphical representation of $\sigma$ vs. $\mu$, this approach also helps in the identification of type II errors since factors with EEs of different signs tend to have a low value of $\mu$ but a considerably higher value of $\sigma$ (Saltelli et al., 2008).

The purpose of this analysis is to investigate the sensitivity of key design inputs upon the performance of the Passivhaus dwellings in a future climatic context. A 2050, $90^{\text {th }}$ percentile year is assessed under a High emissions scenario, for the Islington (5350185) grid cell, in order to reflect a warmer than average mid-century urban climatic context. It is assumed in this assessment that supply and extract ventilation is provided by a whole house MVHR system operating in summer bypass mode (Table 6). In order to test a 'worst case scenario' it is assumed that natural cross ventilation through openable windows cannot be used to cool the dwellings during the summer months due to factors associated with the urban context (such as noise, air pollution and crime).

In this study a limited number $(k=5)$ of influential building parameters were selected in order to assess their influence upon a range of critical performance characteristics. The parameters evaluated were chosen to reflect factors which might typically be within the designers influence in this particular context. In practice a larger or smaller set of input parameters may be selected depending on computational resources (e.g. whether the sensitivity analysis can be fully automated) and whether the influence of other parameters (e.g. orientation, solar absorptance coefficients etc.) are considered to be of interest. The range through which the designer is realistically capable of influencing these values (on any given project) defines the minimum and maximum (lower and upper bounds) of the parameters. In practice the bounds of the range are almost always context dependent and are likely to be constrained by a number of issues including: site layout, building regulations, planning policies, structural considerations, cost implications, Passivhaus criteria, the contractor's expertise etc.

For the purpose of this case study the following input distributions are described, either as discrete values or as uniform $(\mathrm{min} / \mathrm{max})$ ranges:

1 Thermal mass (Discrete distribution; based on, lightweight (LW), mediumweight (MW) and heavyweight (HW) mass options - see Table 5). 
2 Glazing percentage on south side (Uniform distribution; based on percentage of south facing façade area)

3 External shading device transmission factor (Uniform distribution; based on external shutters shading ratio)

4 Airtightness (Uniform distribution; based on normalised $n_{50}$ value in accordance with EN832, assuming a moderate screening, screening coefficient $\mathrm{e}=0.07$ )

5 Internal gains (Discrete distribution; based on the non-occupant related effective internal gains component), see section 4.2.2.1

Table 3 Sensitivity analysis parameters

PARAMETER

Discrete

Uniform

Uniform

Uniform

Discrete

transmission factor on

south facade

4. Airtightness $\left(\mathrm{ach}^{-1}\right)$

5. Internal gains (excl.

occupant gains)

2. Glazing ratio on south facade

\section{MIN - MAX (OR}

\section{DISCRETE VALUES)}

light, med, high

$10-60 \%$

$0-100 \%$

$0-100 \%$

Discrete 
Dynamic thermal simulations were first carried out for a series of base case scenarios in order to establish the overall trend in key performance characteristics between the four dwelling models from the historic (1961-1990) reference period through to 2080, under a High (A1FI) emissions scenario. The purpose of the base case assessment was to establish the comparative performance and temporal trends exhibited by the four dwellings types over a notional 100 year time period.

The deterministic assessments carried out for the base case scenario were followed by a sensitivity analysis of the three Passivhaus dwellings for a range of individual interventions (listed in Table 7). The sensitivity analysis was carried out under a $2050 \mathrm{High}$ (A1FI) emissions $90^{\text {th }}$ percentile TRY scenario, in order to establish which design factors would most significantly influence the key performance outputs of the Passivhaus dwellings, at their mid-life stage (under a warmer than average probabilistic scenario).

\subsection{Base Case - Transitional Assessment of 4 dWellings Under a High Emission SCENARIO (1970-2080)}

The base case assessments were carried out for the four dwellings with specifications given in Table 5. The purpose of the assessments was firstly to establish whether the models were complying with the designated baseline energy performance standards (FEES and Passivhaus respectively). The base case also provides a comparative indication of the evolution of key performance criteria with respect to time. In order to establish a comparative estimate of performance between a dwelling built to the FEES standard $(\mathrm{ZCH}, 2009)$ and dwellings designed to the Passivhaus standard (Feist et al., 2012) identical forms, internal volumes, glazing ratios and purge ventilations strategies (Table 6) were used in all dwellings.

Figure 26 and 27 show that the FEES dwelling is performing in accordance with the limiting SHD criteria, for an end-of-terrace dwelling of $\mathrm{q}_{H} \leq 46 \mathrm{kWh} / \mathrm{m}^{2} . \mathrm{yr}(\mathrm{ZCH}, 2009)$. Similarly all of the Passivhaus dwellings fulfil the SHD criteria of $\mathrm{q}_{\mathrm{H}} \leq 15 \mathrm{kWh} / \mathrm{m}^{2}$.yr (Feist et al., 2012).

The general trends illustrated by Figure 26 - Figure 30 show that SHD will fall significantly in all of the four dwellings under a 'High' (A1FI) scenario, between the historic control period and the 2080's. In the case of the FEES dwellings under a $50^{\text {th }}$ percentile TRY the SHD is predicted to fall by approximately $34 \%$ whilst the Passivhaus dwellings SHD falls by $63 \%$ on average. 


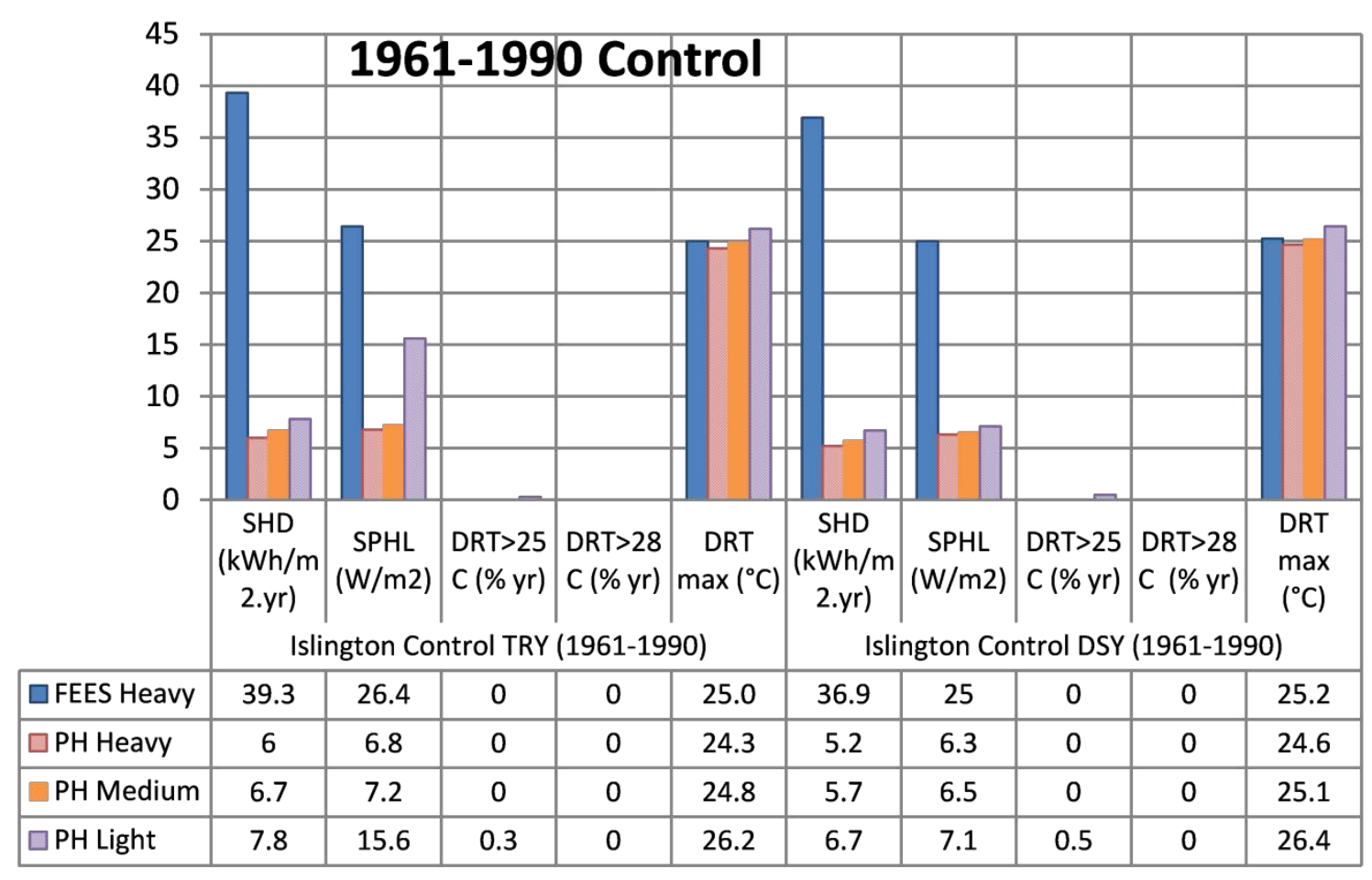

Figure 4 Key outputs 4 dwellings (Islington, 5350185), TRY and DSY control scenario (1961-1990)

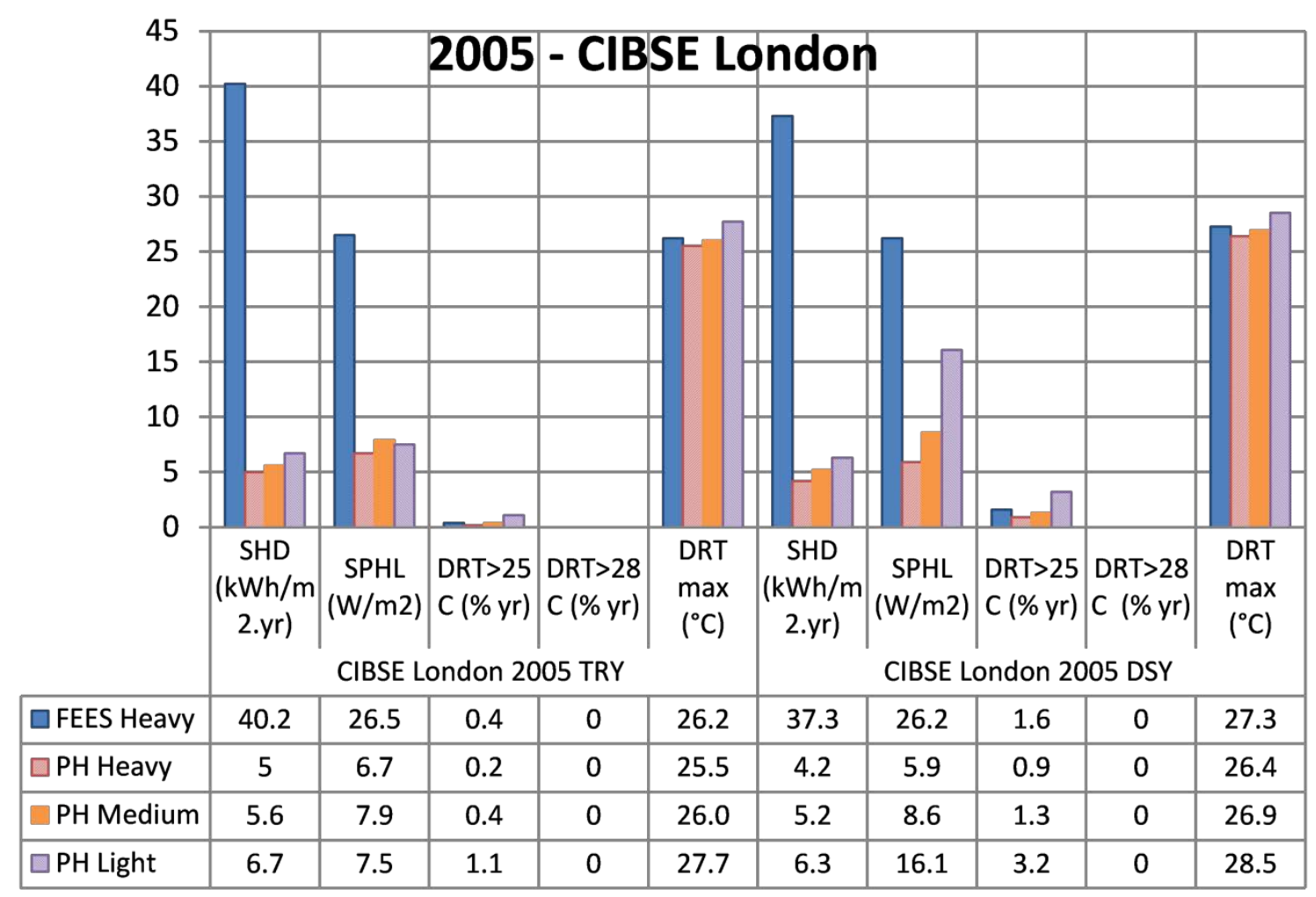

Figure 5 Key outputs 4 dwellings (London Weather Centre), TRY and DSY current day scenario (CIBSE 2005) 


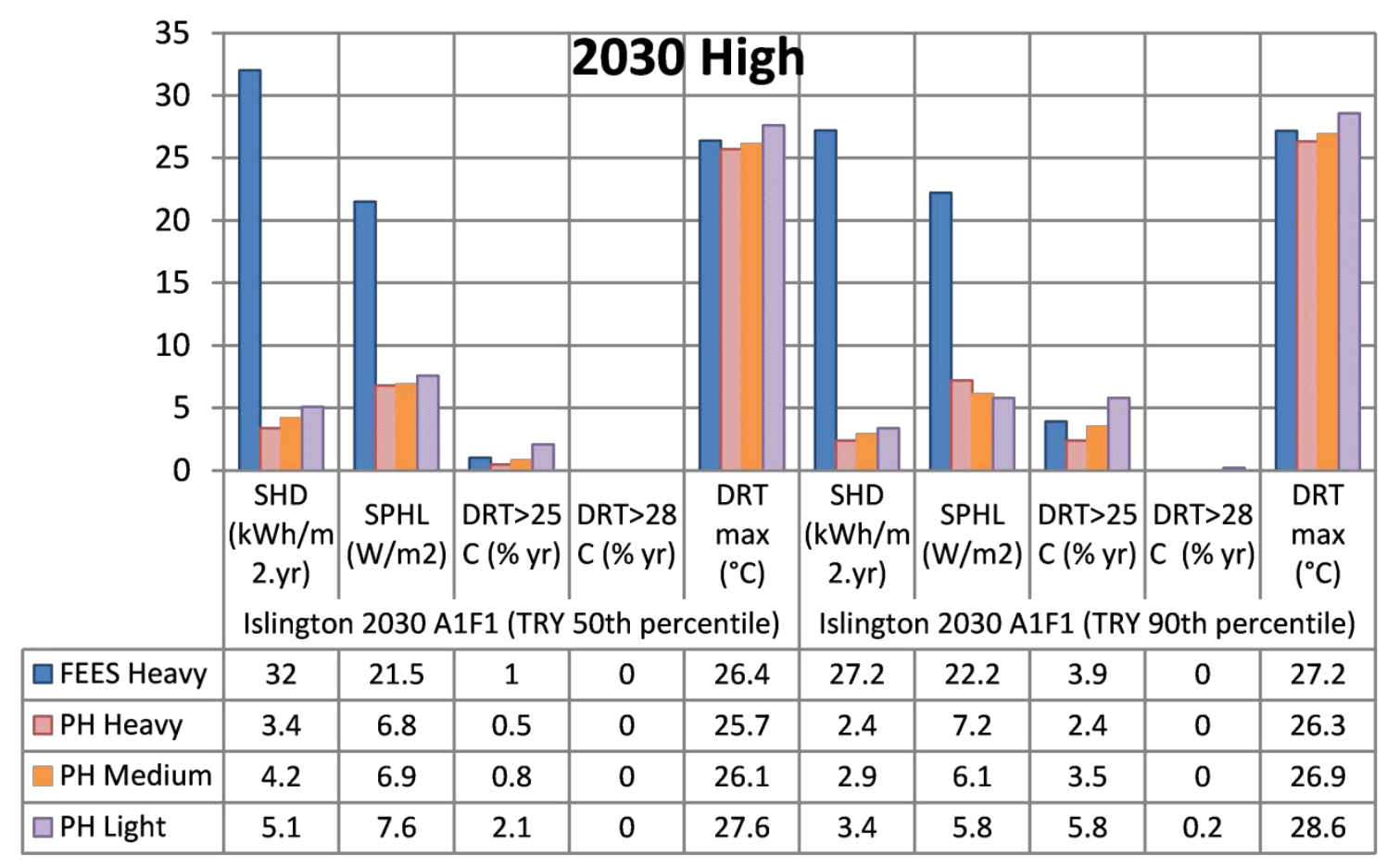

Figure 6 Key outputs 4 dwellings (Islington, 5350185), TRY50th and TRY90th percentile (2030 High)

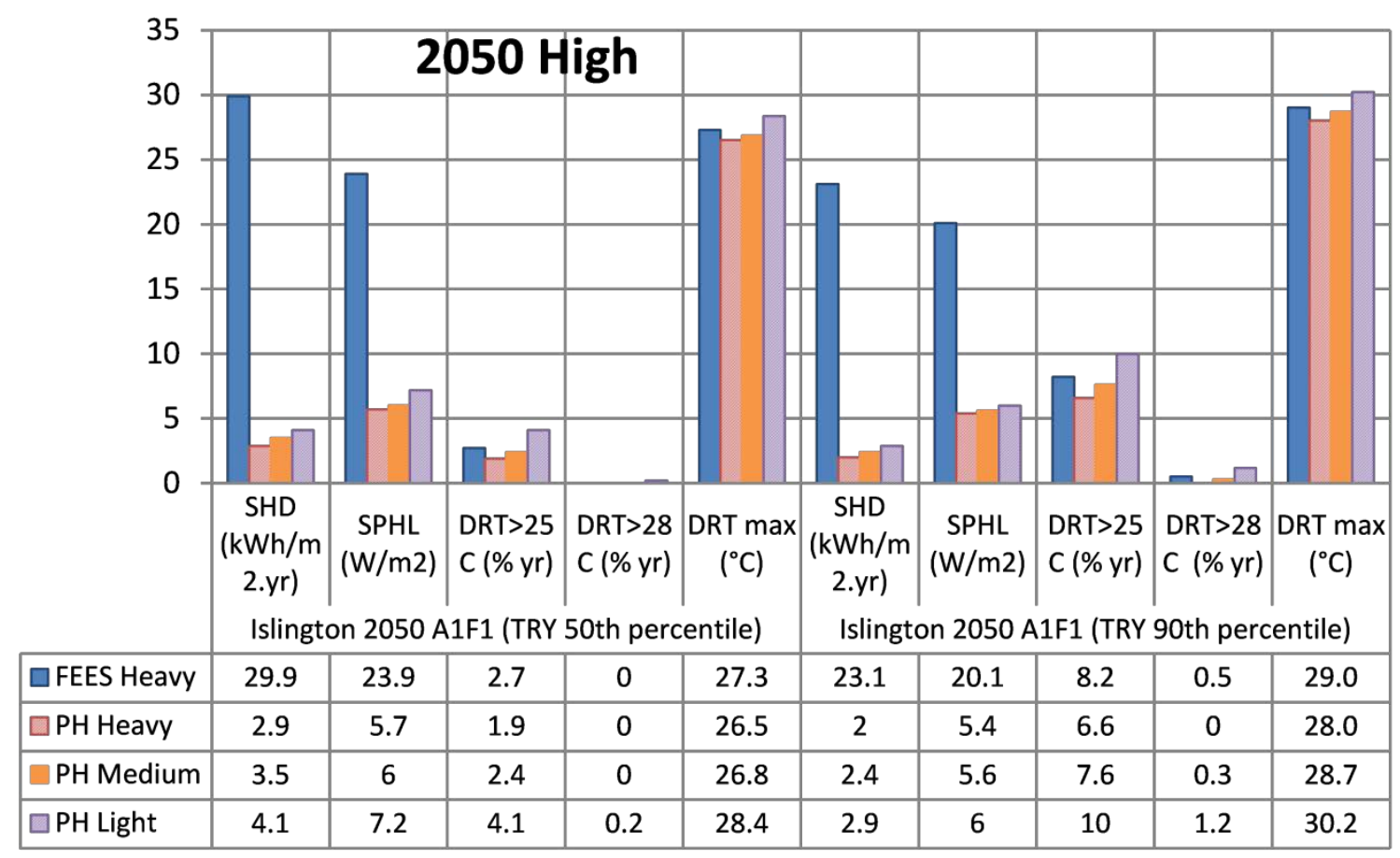

Figure 7 Key outputs 4 dwellings (Islington, 5350185), TRY50th and TRY90th percentile (2050 High) 


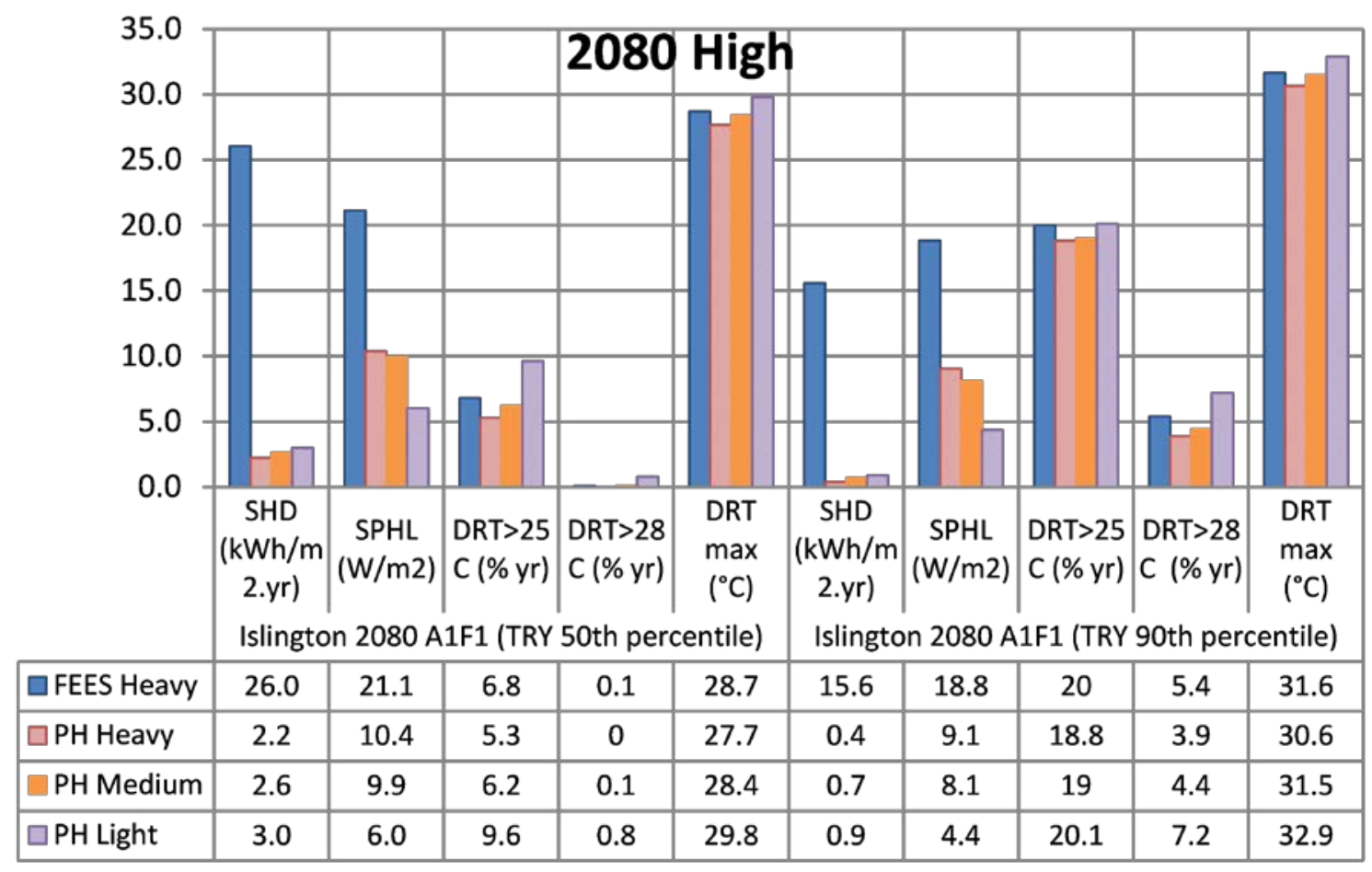

Figure 8 Key outputs 4 dwellings (Islington, 5350185), TRY50th and TRY90th percentile (2080 High)

The overall trend in Specific Peak Heating Load (SPHL) (Figures 26- 30) is far less pronounced than the evolution in SHD, suggesting that whilst the overall climatic trend is warming significant cold periods will continue to exert an influence on peak heating loads in all of the dwellings through to 2080. Beyond the present day (CIBSE 2005) period, the SPHL in all Passivhaus dwellings remained $\leq 10 \mathrm{~W} / \mathrm{m}^{2}$ even when assessed at an hourly time step. By contrast the SHL in the FEES dwelling fell slightly over the same period but remained above $20 \mathrm{~W} / \mathrm{m}^{2}$.

In contrast to falling heating demand, the risk of overheating rose in all dwellings from the control period through to 2080 . The transition towards an increased risk of overheating under both a $50^{\text {th }}$ and $90^{\text {th }}$ percentile TRY as predicted by three performance indicators $\left(\mathrm{OT}_{25}, \mathrm{OT}_{28}\right.$ and $\left.\mathrm{OT}_{\max }\right)$ is illustrated in Figure 30. 
Transitional overheating risk (5350185) TRY 50th percentile

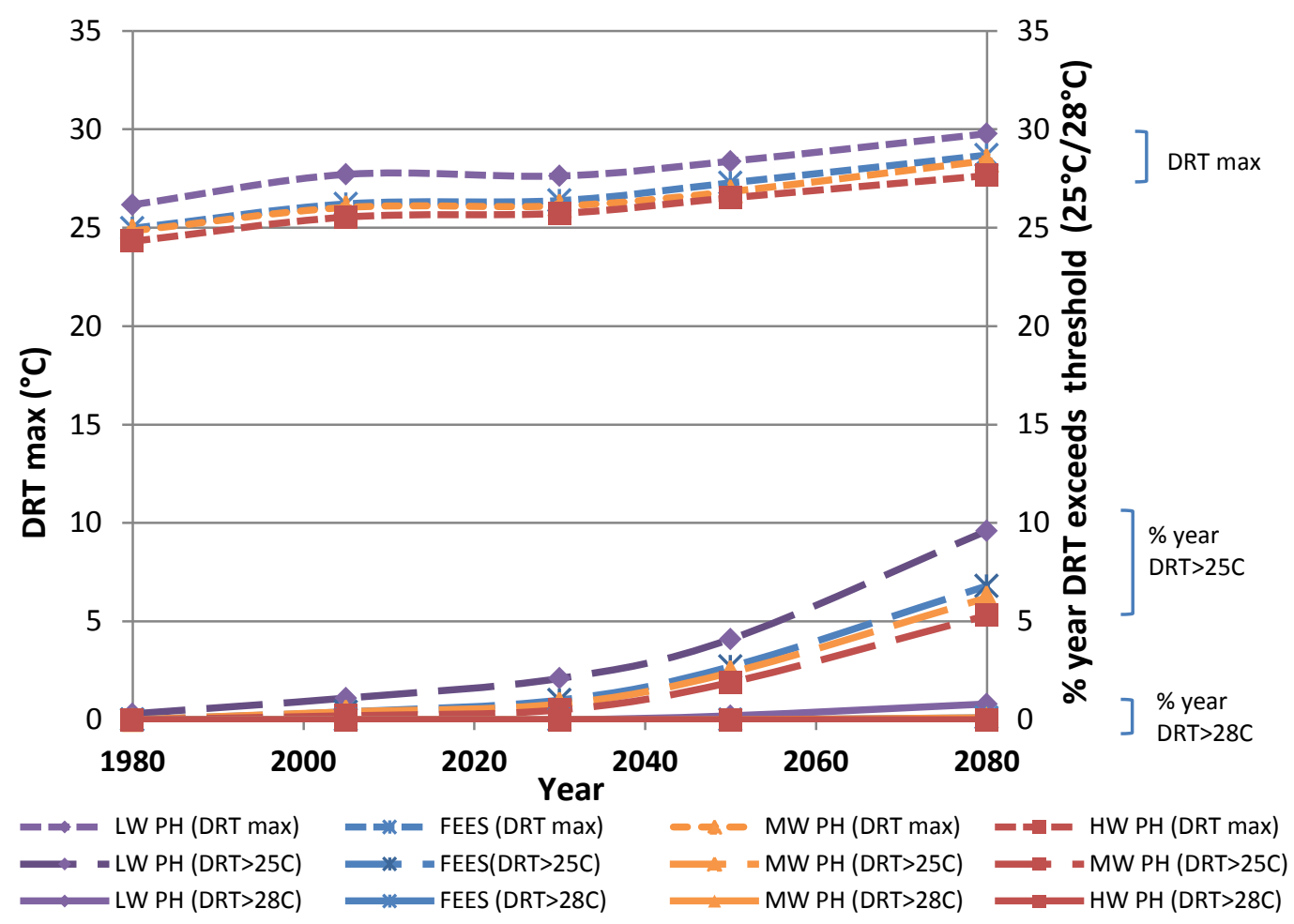

Transitional overheating risk (5350185) TRY 90th percentile

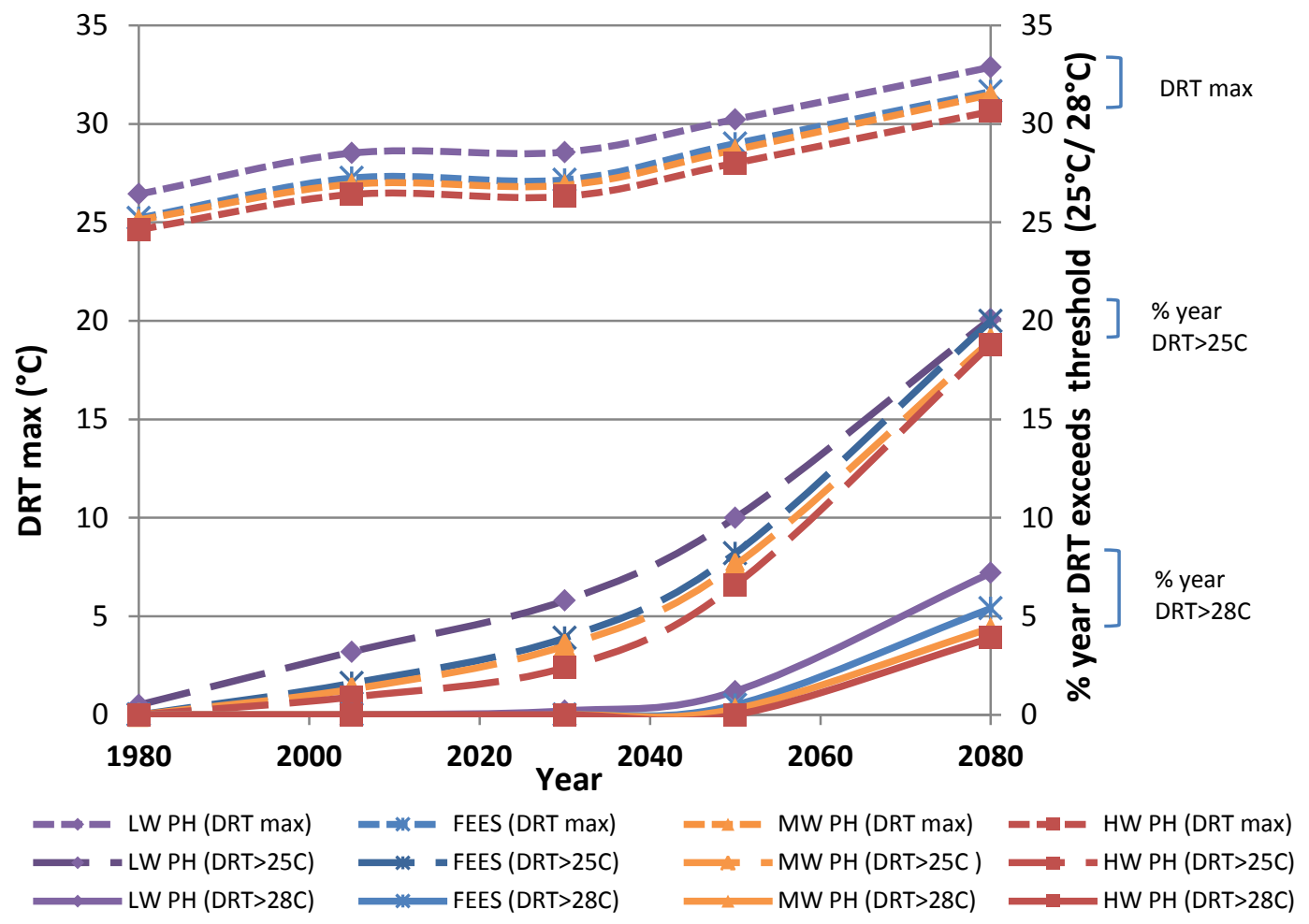

Figure 9 (a) Transitional overheating risk for 4 dwellings at 50th percentile TRY and (b) 90th percentile TRY under a High emissions scenario (1980-2080)

In terms of overheating risk it is notable that the FEES (heavyweight) dwelling performed only slightly worse than the MW Passivhaus overall. This finding suggests that the Passivhaus concept 
(without additional shading or cooling systems) offers only a slight advantage over the more conventional FEES dwelling typology in respect to overheating risk mitigation (assuming comparable design strategies).

It can be seen (Figure 31) that by 2050 under the 90th percentile TRY scenario all of the dwellings are exceeding both the HHSRS criteria (ODPM, 2006) and Voss's $25^{\circ} \mathrm{C}$ criteria (Voss et al., 2005) for more than $5 \%$ of the year, with the LW Passivhaus also exceeding the PHI 10\% overheating criteria at this stage. By 2050 the LW Passivhaus has also exceeded the CIBSE $28^{\circ} \mathrm{C}$ threshold for more than $1 \%$ of the year, and by 2060 all of the dwellings are predicted to overheat beyond the CIBSE $28^{\circ} \mathrm{C}$ threshold for more than $1 \%$ of the year. Under a 50th percentile TRY scenario the same overheating frequencies are not likely to occur until 2080. By 2080 even in an average (50th percentile) year all of the dwellings will be at risk of overheating beyond $25^{\circ} \mathrm{C}$ for more than $5 \%$ of the year.

For the period up to 2050 these findings are in agreement with the findings for overheating risks in dwellings published in CIBSE TM36 which suggests that "buildings with very good control of solar shading, ventilation and internal heat gains can meet targets until the 2050s" (CIBSE, 2005a, p.1). However where CIBSE TM36 states, "In living areas, use of high mass construction enabled the performance targets to be met into the 2080s" (CIBSE, 2005a, p.1). This study found that the same performance targets could not be met in the 2080's by any of the dwelling typologies analysed (even under the 50th percentile TRY scenario). It is notable however that the TM36 (2005) assessments were based on earlier UKCIP02 Medium-High emission scenario climatic predictions, in comparison to the UKCP09 High emission scenario used in this study.

In practical terms these findings suggest that, even with moderate areas of south facing glazing (33 $\%$ by internal façade area), restricted natural ventilation strategies (see section 4.2.1.2) alone are unlikely to provide sufficient means of eliminating the risk associated with prolonged periods of overheating in any of the low energy dwelling types.

In living areas it is apparent that thermal mass appears to offer some benefit both in terms of reducing the frequency of overheating and also the amplitude of the maximum internal temperature (by approximately $2^{\circ} \mathrm{C}$ on average). By 2080 , as the duration of warmer temperatures become more prolonged, the benefits of thermal mass in reducing the frequencies of temperatures above $28^{\circ} \mathrm{C}$ appears to diminish (Figure 31). 


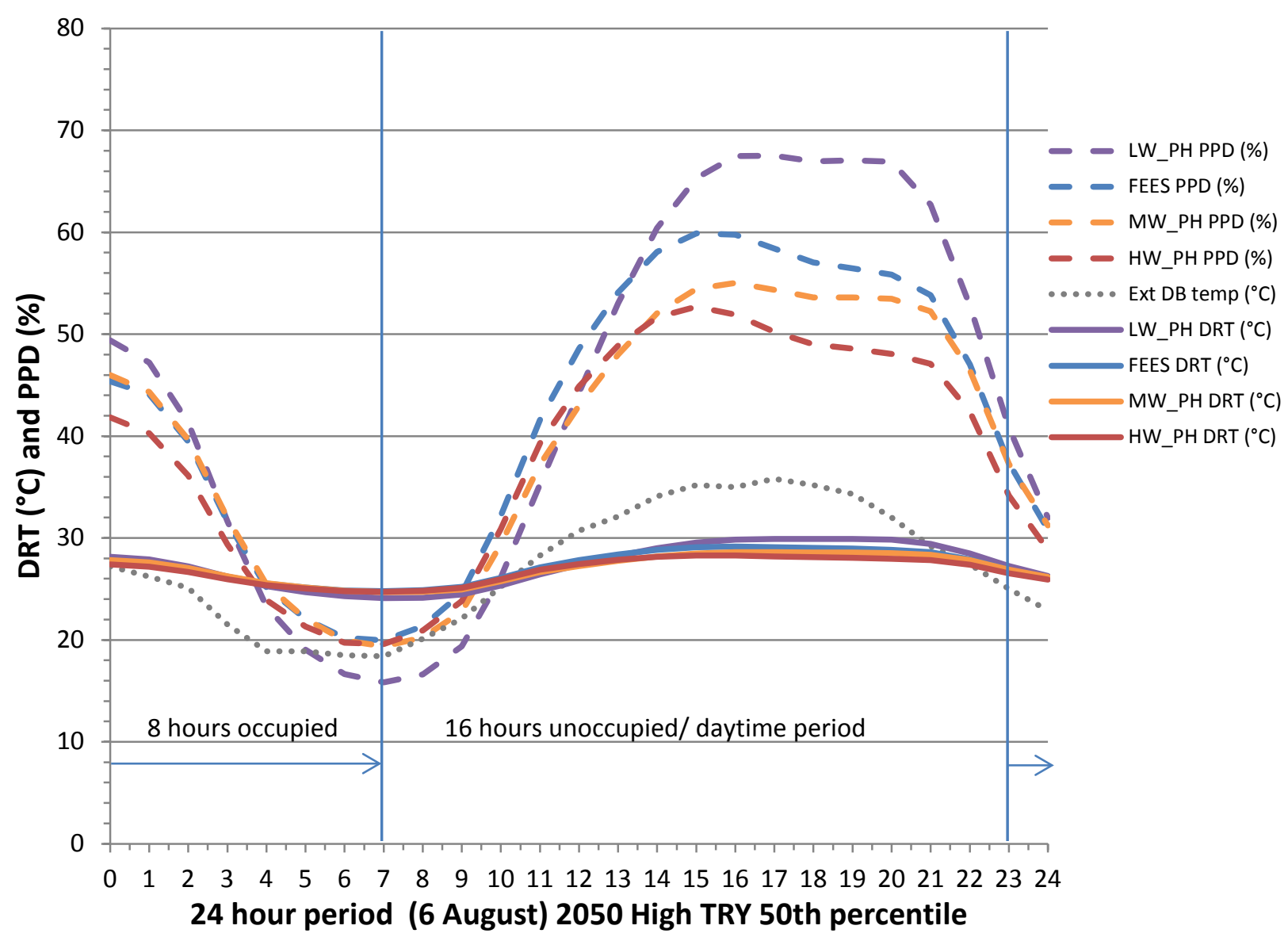

Figure 1024 hour cycle showing Bedroom Dry Resultant Temperatures $\left({ }^{\circ} \mathrm{C}\right)$ and Predicted Percentage Dissatisfied (\%) during the hottest period of 2050 High (TRY 50th percentile) year

In the bedrooms the benefits of thermal mass in reducing overheating risks are less obvious. Despite higher daytime temperatures the lightweight Passivhaus cools more rapidly during the night-time period than the heavier weight dwellings (Figure 32). As a result for approximately half of the occupied period (11 pm -7 am) the lightweight Passivhaus achieves a lower Predicted Percentage Dissatisfied (PPD) vote than the other dwellings. The precise point at which the dwellings begin to cool is affected by the thermal inertia of the building and the timing of the peak external dry bulb temperatures. In an urban context the duration and intensity of the afternoon temperature peak may be strongly influenced by the magnitude and the timing of the peak intensity of the UHI effect (section 4.2.3.1), and hence it is essential to assess the benefits of thermal mass in a context specific manner. Whilst thermal mass can be seen to play a useful role in dampening maximum internal temperatures it can also delay the rate and extent of night-time cooling (Figure 32). Overall these finding suggests that the benefits of thermal mass in reducing the frequency of overheating during prolonged overheating spells may diminish in urban contexts during the latter part of this century and warrants further investigation. 


\subsection{SENSITIVITY ANAlysis of Key Design InPUTS - 2050 High EMISSION SCENARIO}

The results of the EE sensitivity analysis are shown as scatter plots (Figure $35 \mathrm{a}-\mathrm{f}$ ) where each point represents the influence of a single individual input variable $(i)$ upon the selected output. The input variables and input variable ranges are shown in Table 7. For clarity the number of input variables has been limited to 5 in this initial analysis, although in theory consideration of an unlimited number of variables is possible given sufficient computational resources. The $x$-axis in the scatter plots (Figure 35 a-f) represents the absolute mean $\left(\mu_{i}{ }^{*}\right)$ of the EE's, a measure of the absolute importance of the input factor $(i)$. The $y$-axis represents the standard deviation $\left(\sigma_{i}\right)$ of the EE's, a measure of the extent which the effects are non-linear or result from interactions with other factors.

The ratio $\left(\sigma_{i} / \mu_{i}^{*}\right)$ can thus be seen as an indicator of linearity for the input factor $(i)$, where a true linear response would occur in the case that $\sigma_{i} / \mu_{i}^{*}=0$, since $\lim _{\sigma i \rightarrow 0}\left(\frac{\sigma i}{\mu i *}\right)=0$. According to the theory of normal distribution, where the EE's take the form of a general normal distribution then $95 \%$ of the EE dispersions will lie within the range of $\mu_{i} \pm 1.96 \sigma_{i}$ (Montgomery and Runger, 2011). Thus if $\sigma_{i} \leq$ $0.1 \mu_{i}$ then $95 \%$ of the EE's will lie in a range $\mu_{i} \pm 20 \%$. Where the ratio $\sigma_{i} / \mu_{i} \leq 0.5$, most EE's $(95 \%$ with a normal distribution) will have the same sign and the model response can be considered monotonic with respect to the input variable $i$ (Sanchez Garcia et al, 2012).

In the context of building simulation models, the distribution of elementary effects for a given input factor is unlikely to follow a theoretical normal distribution, a scatter plot analysis of the relationship between $\left(\sigma_{i} / \mu_{i}^{*}\right)$ vs. $\sigma_{i} / a b s\left(\mu_{i}\right)$ (Figure 33) is therefore a useful diagnostic method for identifying monotonic behaviour in the model (Garcia-Sanchez et al, 2012). The monotonic interval is found where the ratio $\left(\sigma_{i} / \mu_{i}^{*}\right)$ vs. $\sigma_{i} / a b s\left(\mu_{i}\right)$ scatter points are located on or near the bisector, which can be seen to extend slightly beyond $\left(\sigma_{i} / \mu_{i}^{*}\right) \leq 0.5$ in Figure 33. Highly scattered EE's occur where $\sigma_{i}$ $\operatorname{labs}\left(\mu_{i}\right)>1$ indicating factors where marked non linearity and interactions with other factors are taking place, this occurs in the interval $\left(\sigma_{i} / \mu_{i}^{*}\right) \geq 0.5$, with highly scattered EE's occurring at $\left(\sigma_{i} / \mu_{i}^{*}\right) \geq$ 1.0 (Figure 33). The delineation of slope gradient lines at $\sigma_{i} / \mu_{i}{ }^{*}=0.1,0.5$, and 1 thus provides a useful framework for the subsequent assessment of the linearity of the EE's associated with each input variable in Figure $35 \mathrm{a}-\mathrm{f}$. 


\section{$\sigma_{i} / \mu_{i}^{*}$ versus $\sigma_{i} / a b s\left(\mu_{i}\right)$}

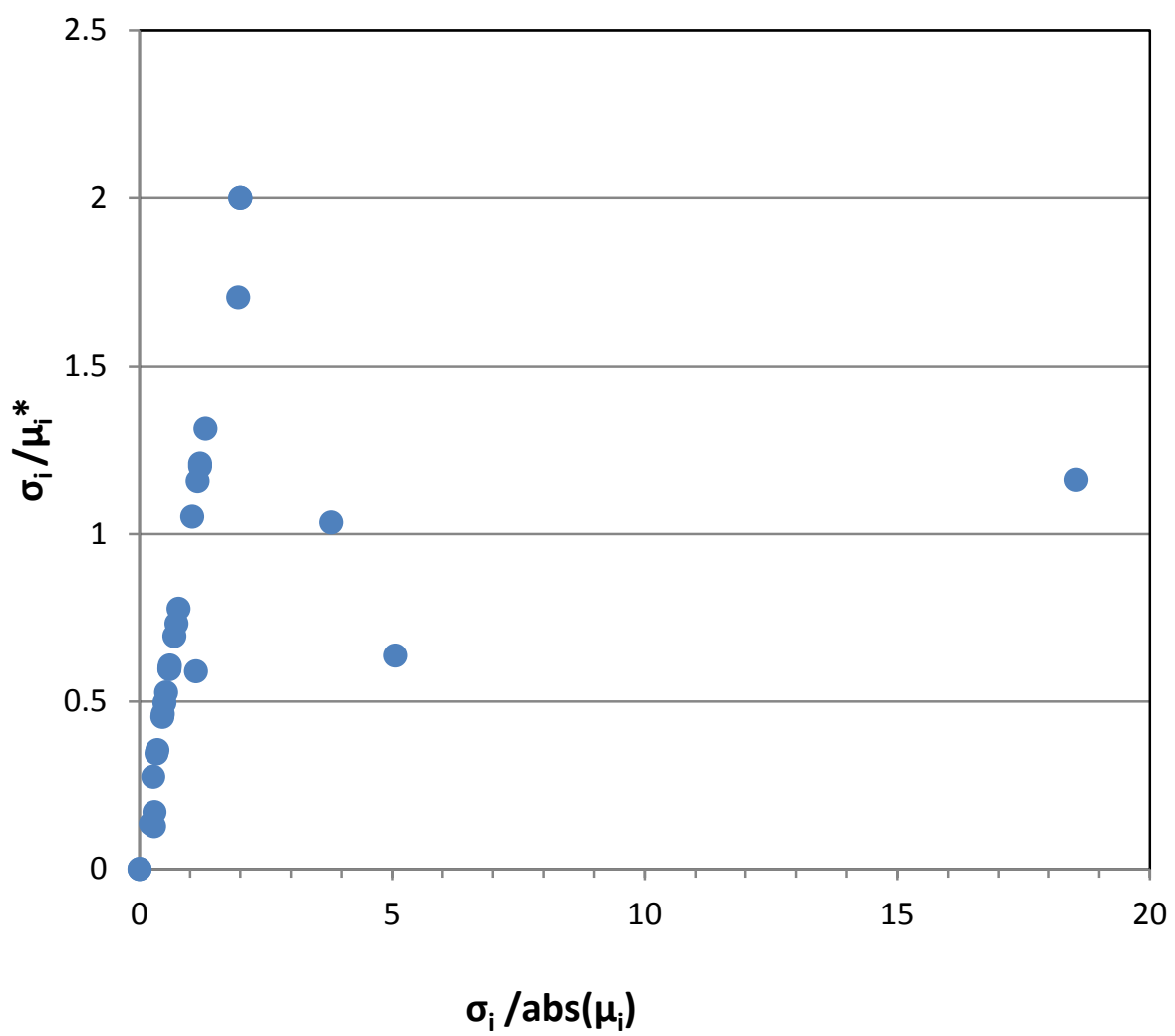

Figure 11 Relationship between $\sigma_{\mathrm{i}} / \mu_{\mathrm{i}}{ }^{*}$ and $\sigma_{\mathrm{i}} / \mathrm{abs}\left(\mu_{\mathrm{i}}\right)$ for a combination of 30 elementary effects

The far right hand outlier (Figure 33) is the output for the frequency of the DRT>28C in response to the internal gains input factor, which indicates that $a b s\left(\mu_{i}\right)$ is significantly smaller than $\mu_{i}{ }^{*}$, for this factor. This finding suggests that the internal gains are having a non-monotonic effect on the frequency of the DRT $>28^{\circ} \mathrm{C}$ (in contrast to the linear effect of the internal gains on the frequency of the DRT $>25^{\circ} \mathrm{C}$ ). This finding is unexpected and is likely to be a result of interactions with other factors, which could only be revealed through an analysis of the second and higher order effects. 
The mean of the absolute EE's $\left(\mu_{i}^{*}\right)$ for each input factor $(i)$ is considered a good proxy of the total sensitivity index $\left(\mathrm{S}_{\mathrm{T}}\right)$ (Campolongo, 2007; Saltelli et al, 2008). Figure 34 ranks input/output sensitivity for a combination of 6 outputs in relation to 5 inputs factors.

\section{Sensitivity ranking of combined factors}

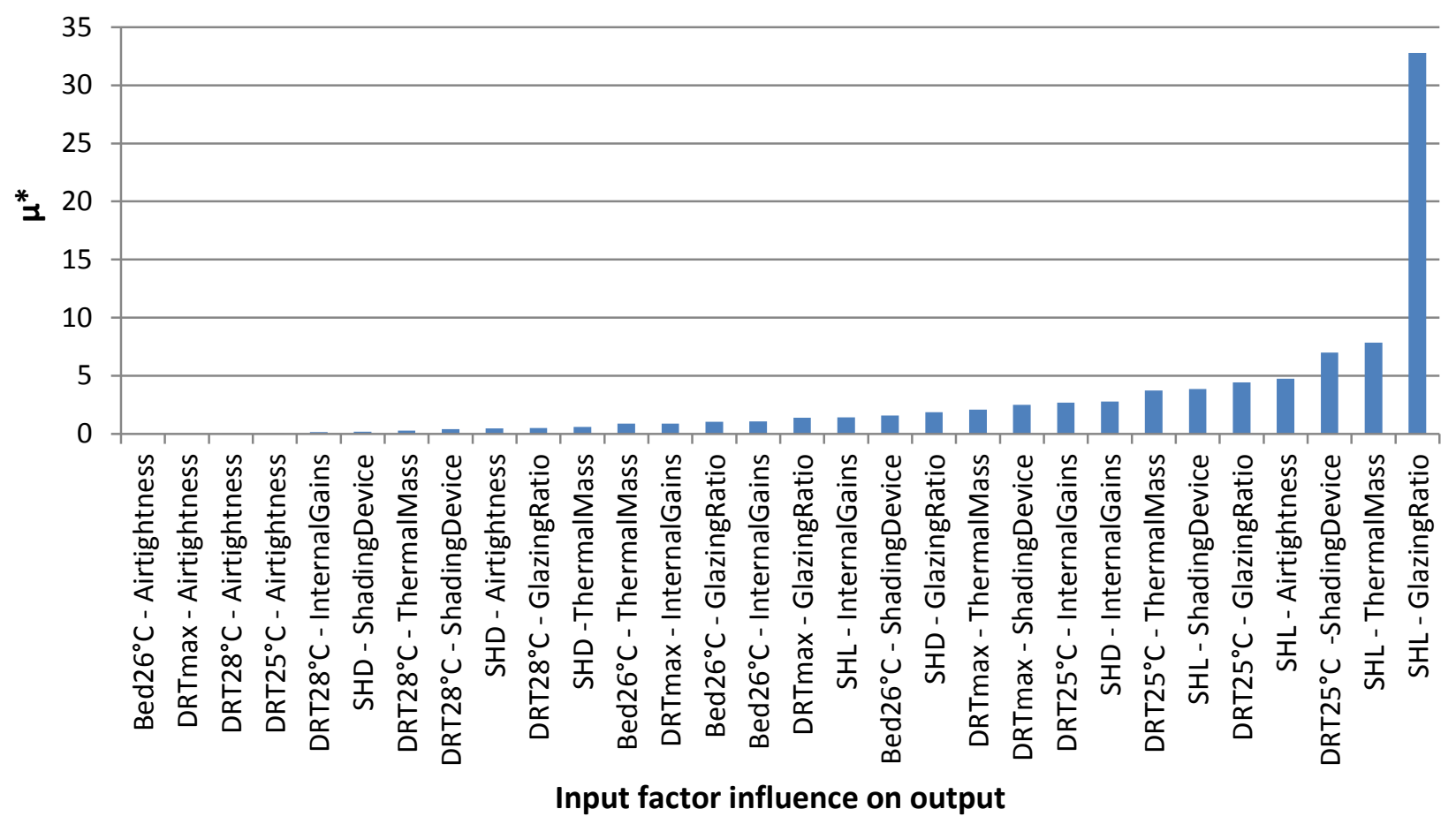

Figure 12 Ranking of output factor sensitivity - combined measures

The output factor sensitivity ranking shown in Figure 34 provides useful information at the conceptual design stage. For example the ranking illustrates that the SHL is highly sensitive to the glazing-to-wall ratio used in the model, and that this factor is four times more important than the dwelling's thermal mass in influencing the SHL (in relation to the ranges assessed in Table 7). This information is particular relevant in the planning process where either the SHD $\leq 15 \mathrm{kWh} / \mathrm{m}^{2}$.yr or $\mathrm{SHL} \leq 10 \mathrm{~W} / \mathrm{m}^{2}$ criteria may be used to comply with the Passivhaus certification criteria (Feist et al, 2012).

The ranking of the overheating variables (Figure 34) provides a hierarchy for minimising the future overheating risk. It can be seen from this analysis that the influence of the external shading device has the greatest potential effect upon the frequency of internal temperatures above $25^{\circ} \mathrm{C}$, followed by the (south facing) glazing-to-wall ratio (within the ranges assesses in Table 7). At the opposite end of the scale improving airtightness (beyond $n_{50} \leq 0.6 \mathrm{~h}^{-1}$ ) can be seen to have negligible impact upon any of the overheating parameters. In practice the use of hierarchical ranking also exposes optimization synergies. For example it can be seen (in Figure 34) that designs optimized in relation to 
the SHL shows a better correlation with factors that will also result in reduced overheating risks, than designs optimized in favour of the SHD.

In a first order analysis, the value of an elementary effect for an individual input variable $(i)$ corresponds to the output variation when the input $i$ moves from the minimum scalar function $(0)$ to the maximum (1). By averaging the EE's of $r$ random trajectories the dependence on a single sampling point is removed and $\mu_{i}^{*}$ becomes a good proxy for the mean output variation corresponding to the input $i$. By plotting $\mu_{i}{ }^{*}$ against $\sigma_{i}$ (Figure $35 \mathrm{a}-\mathrm{f}$ ) it is possible to graphically identify factors which are almost linear (below $\sigma_{i} / \mu_{i}^{*}=0.1$ ), monotonic $\left(0.1<\sigma_{i} / \mu_{i}^{*}<0.5\right)$, almost monotonic $\left(0.5<\sigma_{i} / \mu_{i}^{*}<1.0\right)$, and factors with which are highly non-linear or interacting with other factors $\left(\sigma_{i} / \mu_{i}^{*}>1\right)$ (Figure $\left.35 \mathrm{a}-\mathrm{f}\right)$. 
(a) Specific Heat Demand

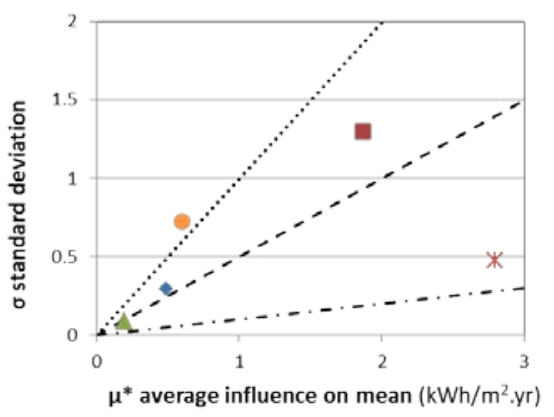

(c) Frequency of DRT $>25^{\circ} \mathrm{C}$

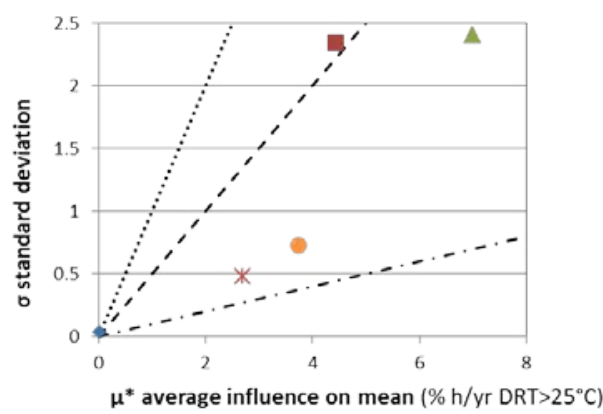

(e) Frequency of bedroom DRT $>26^{\circ} \mathrm{C}$

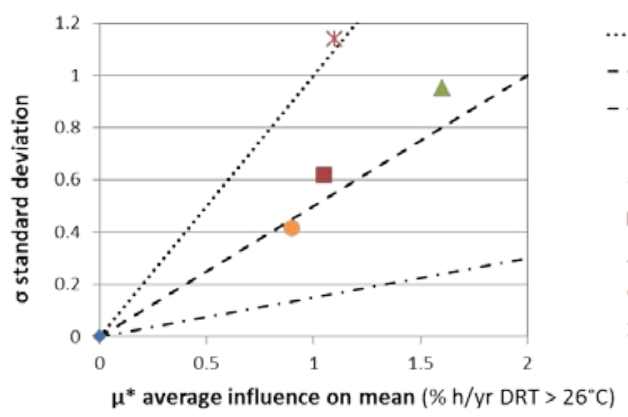

(b) Peak Heating Load

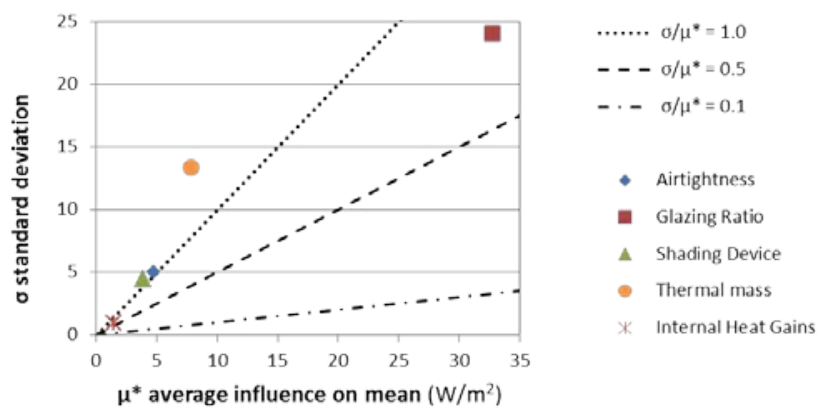

(d) Frequency of DRT $>28^{\circ} \mathrm{C}$

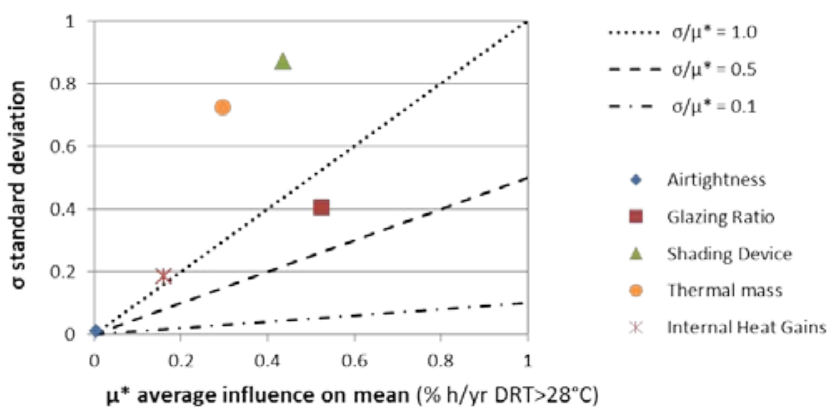

(f) Absolute DRT $\max { }^{\circ} \mathrm{C}$

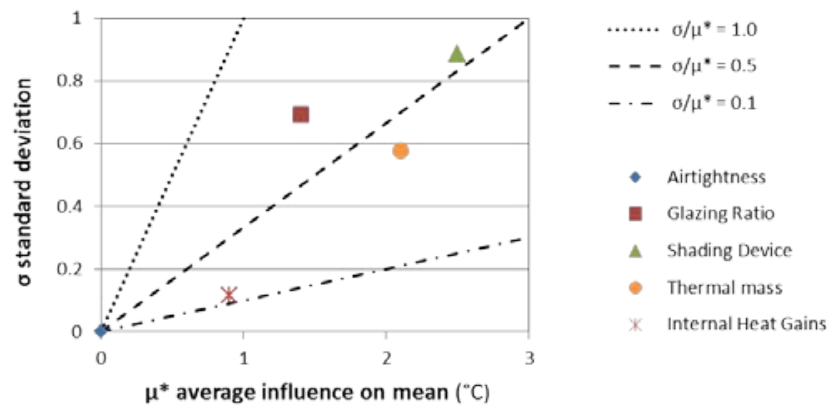

Figure 13 Enhanced Morris analysis of absolute mean $\left(\mu^{*}\right)$ and standard deviation $(\sigma)$ of first order elementary effects for (a) space heating demand (b) peak heating load (c) living area DRT above $25 \mathrm{C}$ (d) living area DRT above $28 \mathrm{C}$ (e) bedroom DRT above $26 \mathrm{C}$ and (f) living area maximum DRT

Figure 35a shows that internal gains have a significant and monotonic effect on the SHD, yet play only a small role in influencing the SHL. The SHL (Figure 35b), is most strongly influenced by the glazing ratio (as shown by Figure 34) in an almost monotonic manner. In contrast thermal mass also exerts a significant influence on the SHL (Figure 35b), however its influence is highly non-linear suggesting that possible interactions with other factors are occurring.

In terms of the overheating parameters the most pronounced influence of the input parameters can be seen on the frequency of the $\mathrm{OT}_{25}$ (Figure 35c), since the influence of all passive design factors diminishes as the overheating threshold is elevated (Figure $35 d, e, f)$. The shading device has the most pronounced influence upon the frequency of $\mathrm{OT}_{25}$ and also the frequency of BedOT ${ }_{26}$. Interestingly 
internal gains appear to play a more significant role in influencing the frequency of BedOT 26 (Figure $35 e)$ than in the combined living area overheating parameters. One possible explanation of this finding is that internal sources of heat are likely to contribute to internal air temperature stratification which will be experienced more strongly in the first floor bedrooms due to the buoyancy effect.

Overall the SHL (Figure 35b) sensitivity analysis is better correlated with the overheating parameters than the SHD (Figure 35a). This finding suggests that there are likely to be less parameter conflict in a Passivhaus dwelling that is optimized for low SHL and low overheating risks than for a dwelling designed for low SHD and low overheating risks.

\section{CONCLUSIONS}

Evidence suggests that Passivhaus and super insulted dwellings are already at risk of overheating in the UK, Ireland and Northern Europe. In the rapid transition to zero carbon building in the UK, designers of Passivhaus and low energy dwellings are currently at risk of pursuing ultra-low space heating targets at the expense of whole life thermal performance. According to the results of this study by 2050 a warmer than average summer could see average internal temperatures (in Passivhaus and low energy FEES dwellings) in London exceeding $25^{\circ} \mathrm{C}$ for between $5-10 \%$ of the year. Beyond 2050, in warmer than average summer conditions, the duration of mean internal temperatures above $28^{\circ} \mathrm{C}$ rises sharply in all of the dwelling types studied. Unless there is a move towards whole life design optimization based on minimising future overheating risks, active cooling systems may become a de-facto requirement in urban Passivhaus and low energy dwellings in the UK within the next $30-40$ years.

If global GHG emissions continue to follow a 'High' (A1FI) emissions scenario trajectory then the average SHD of Passivhaus dwellings in London is likely to fall considerably (by approximately 40\%) by the middle of this century, whilst at the same time the $\mathrm{SHL}$ is likely to remain substantially unchanged. In relation to overheating risk factors, the Passivhaus concept (when used without active cooling systems) appears to provide only slight additional protection in comparison to an almost identical naturally ventilated FEES dwelling.

The performance of the Passivhaus dwellings in this study was shown to be highly sensitive to a small number of design inputs. In particular the risk of overheating (OT frequency above $25^{\circ} \mathrm{C}$ ) was shown to be highly dependent upon the solar transmission reduction provided by a full external shading device, as well as the glazing to wall ratio on the South façade. Glazing to wall ratios also 
played a dominant role in relation to the peak heating load. It follows therefore that design optimization in relation to the SHL, as opposed to SHD, is likely to produce better outcomes in relation to overheating risk reduction.

Thermal mass played a clear role in reducing the overall duration of overheating in the Passivhaus dwellings, and was also correlated with a reduction in the SHL. In relation to reducing the SHD however, thermal mass had only a minor effect. Further detailed investigations regarding the effects of thermal mass in relation to the timing of the dampening effect (decrement delay) during prolonged heatwaves (where night purge ventilation possibilities are limited) is needed. The results here suggest that the use of thermal mass may be counter indicated in relation to overheating risks in bedrooms in some cases. More sophisticated systems involving the use of displaced thermal mass (via earth air heat exchangers) or Thermally Active Building Systems (TABS) may overcome these problems and be worthy of further investigation.

Careful attention must be paid to the design assumptions and assessment criteria used to evaluate future overheating risks. The methods currently used to prepare TRY and DSY datasets involve the use of a statistical filtering procedure (the Finkelstein Schafer statistic) a process which tends to smooth out extreme day to day variability in the creation of 'representative' weather years. As a result heat wave events are not reliably modelled by the use of these climate files regardless of the percentile of the CDF which is used. The use of additional procedures to model extreme weather events is therefore advised.

In urban contexts, the possibilities of purge ventilation through opening windows may be limited or non-existent and internal gains in a UK social housing context may be significantly higher than PHPP defaults suggest. Clearer guidance on acceptable overheating criterion with respect to morbidity and mortality risks as a function of OT's and IAQ is urgently required.

Further research is also needed to establish the full extent of the future overheating risk in a broad range of Passivhaus dwelling typologies and urban contexts. This work is particularly important in relation to dwellings housing vulnerable occupants (including apartments and care homes); where a combination of high internal gains, large glazed areas and reduced purge ventilation possibilities are likely to co-exist. Simple sensitivity analysis techniques, used in conjunction with probabilistic scenario modelling, provide a means of facilitating transient design optimization in the face of rapid climatic change. 


\section{ACKNOWLEDGEMENTS}

The authors would like to acknowledge the data and information kindly made available by Cyril Mannion e Director, Passive House Builders Ltd, Dublin, and Justin Bere e Director, bere:architects, London. This paper is part of an on-going research project investigating the adaptation of the Passivhaus concept to the UK context, which is supported by the BRE.

\section{REFERENCES}

Andersen, K., Heiselberg, P., and Aggerholm, S., 2002. Natural ventilation in commercial buildings. SBI instruction 202. Danish Building Research Institute, 2002

ASHRAE 55, 2004. American Society of Heating Refrigeration and Air-Conditioning Engineers: AINSI/ ASHRAE 55-2005, Thermal Conditions for Human Occupancy, ASHRAE, Atlanta, April 2004

Bere architects, 2012. Larch House - Soft Landings Stage 4, initial aftercare workshop. Video interview with the occupants of the Larch Passivhaus, Ebbw Vale Wales. Available at: http://bere.co.uk/films/larch-house-softlandings-workshop

Aries, M., and Bluyssen, P., 2009. Climate change consequences for the indoor environment. HERON Vol. 54 (2009) No.1: 49-69

Armstrong, B., Chalabi, Z., Fenn, B., Hajat, S., Kovats, S., Milojevic, A., and Wilkinson, P., 2010.

Association of mortality with high temperatures in a temperate climate: England and Wales. Journal of Epidemiology and Community Health 65, 340-5

ARUP, 2005. UK Housing and Climate Change, Heavyweight vs. Lightweight Construction. Arup Research and Development, Bill Dunster Architects, Feilden Clegg Bradley Architects, the RIBA. Available at: http://www.greenspec.co.uk/documents/whitepapers/Climate_Change_BDA_report.pdf ASHRAE, 2001. American Society of Heating Refrigeration and Air-Conditioning Engineers: International Weather for Energy Calculations 1.1 (IWEC Weather Files). Atlanta, 2001. Available at: http://apps1.eere.energy.gov/buildings/energyplus/weatherdata_sources.cfm?print Basu, R., and Samet, J., 2002a. Relation between Elevated Ambient Temperature and Mortality: A Review of the Epidemiologic Evidence. Epidemiologic Reviews (2002) Vol. 24, No. 2: 190-202. DOI: 10.1093/epirev/mxf007. Available at: http://epirev.oxfordjournals.org/ 
Basu, R., and Samet, J., 2002b. An Exposure Assessment Study of Ambient Heat Exposure in an Elderly Population in Baltimore, Maryland. Environmental Health Perspectives (2002) Vol. 110, Number 12: 1219-1224. Available at: http://ehpnet1.niehs.nih.gov/docs/2002/110p1219-1224

Berglund, L., 1978. Mathematical Models for Predicting the Thermal Comfort Response of Building Occupants, ASHRAE Trans., Vol.84, 1978.

Berndgen-Kaiser, A., Fox-Kamper, R., Holtmann, S., 2007. Leben im Passivhaus, in: Baukonstruktion, Baukosten, Energieverbrauch, Bewohnererfahrungen, ILS NRW Schriften 202, Institut fur Landes und Stadtentwicklungsforschung und Bauwesen des Landes Nordrhein-Westfahlen, Aachen, Germany, 2007.

Bouchama, A., and Knochel, J.,2002. Heat stroke. N Engl J Med 346 (2002); 1978-88

Bows, A., and Anderson, K., 2008. Reframing the climate change challenge in light of post-2000 emission trends. Phil. Trans. R. Soc. A. doi:10.1098/rsta.2008.0138. Available at:

http://rsta.royalsocietypublishing.org/content/366/1882/3863.long

Burhenne, S., Elci, M., Jacob, D., Neumann, C and Herkel, S., 2010. Sensitivity analysis with building simulations to support the commissioning process. Proceedings of the Tenth International Conference for Enhanced Building Operations, Kuwait, October 26-28, 2010.

Buysee, D., Grunstein, R., Horne, J., and Lavie, P., 2010. Can an improvement in sleep positively impact on health? Sleep Medicine Reviews (2010): 404-410

Campolongo, F., Cariboni, J., and Saltelli, A., 2007. An effective screening design for sensitivity analysis of large models. Environmental Modelling and Software 22(2007);1509-1518

Campolongo, F., Cariboni, J., Saltelli, A., and Schoutens, W., 2005. Enhancing the Morris Method. In: Sensitivity Analysis of Model Output, 369-379. Available at:

http://publications.jrc.ec.europa.eu/repository/handle/111111111/13169

Carrilho da Graçáa, G., Augusto, A., and Lerer, M., 2012. Solar powered net zero energy houses for southern Europe: Feasibility study. Solar Energy 86 (2012) pp634-646. Available at: www.elsevier.com/locate/solener Cassadou, S., Chardon, B., D’Helf, M., Declercq, C., Eilstein, D., Fabre, P., Filleul, L., Jusot, J., Lefranc, A., Le Tertre, A., Medina, S., Pascal, L., and Prouvost, H., 2004. Vague de chaleur de l'été 2003 : relations entre température, pollution atmosphérique et mortalité dans neuf villes française. 2004 Rapport d'étude, InVS. Available at: www.invs.sante.fr/publications/2004psas9_070904/rapprt.pdf

CDC, 1995. Heat related mortality - Chicago. Morb Mortal Wkly Rep 44(31) 577-579. Centers for Disease Control, July 1995 
CIBSE, 2005a. CIBSE TM36: Climate change and the indoor environment: impacts and adaptation. The Chartered Institution of Building Services Engineers, London: 2005. ISBN 1903287502

CIBSE, 2005b. Guide B: Heating, Ventilating, Air Conditioning and Refrigeration Guidance. The Chartered Institution of Building Services Engineers, London: 2005.

CIBSE, 2006. Guide A: Environmental Design. The Chartered Institution of Building Services Engineers, London: 2006. Issue 2 (January 2007). ISBN-13: 978-1-903287-66-8

Coley, D., Kershaw, T., and Eames, M., 2012. A comparison of structural and behavioural adaptations to future proofing buildings against higher temperatures. Building and Environment 55 (2012) 159-166. Available at: www.elsevier.com/locate/buildenv

Collins, K., and Hoinville, E., 1980. Temperature requirements in old age. Building Services Engineering Research and Technology 1. 165-172

Confalonieri, R., Bellocchi, G., Tarantola, S., Acutis, M., Donatelli, M., and Genovese, G., 2010. Sensitivity analysis of the rice model WARM in Europe: Exploring the effects of different locations, climates and methods of analysis on model sensitivity to crop parameters. Environmental Modelling and Software 25 (2010); 479488. Available at: www.elsevier.com/locate/envsoft

Danner, M., Vittar, C., 2001. Wohnen in der Passivhaussiedlung Lummerland im Neubaugebiet HannoverKronsberg, final report, 2001. Available at: http://enercity.de/myenercity/Passivhaus/urkonzept.pdf Eames, M., Kershaw, T., and Coley, D., 2012. The appropriate spatial resolution of future weather files for building simulation. Journal of Building Performance Simulation, 5:6 (2012) 347-358

EST, 2005a. Building energy efficient buildings using modern methods of construction (CE139). London: Energy Savings Trust and BRE

EST, 2005b. Avoidance of overheating and air-conditioning in urban housing. Watford: Energy Savings Trust and BRE.

Ezratty, V., Duburcq, A., Emery, C., Lambrozo, J., 2009. Residential energy systems: links with socio-economic status and health in the LARES study. Housing and Health in Europe: The WHO LARES Project. Routledge, London

DBRI, 2013. Danish Building Research Institute, Aalborg University, Denmark. BSim - Building Simulation. Available at: www.sbi.dk/en/publications/programs_models/bsim 
DECC, 2011. Planning our electric future: a White Paper for secure, affordable and low-carbon electricity. Presented to Parliament by the Secretary of State for Energy and Climate Change. ISBN: 9780101809924. HMSO, ID: 2437183. July 2011.

DECC, 2012a. Energy Consumption in the UK 2012: Domestic energy consumption in the UK since 1970. URN: 12D/291. Available at: http://www.decc.gov.uk/en/content/cms/statistics/publications/ecuk/ecuk.aspx

DECC, 2012b. Energy Consumption in the UK. Domestic data tables 2012 update. Excel spreadsheet 4186EnergyConsumptionUK-domestic_DECC2012. Available at: http://www.decc.gov.uk/en/content/cms/statistics/publications/ecuk/ecuk.aspx

DCLG, 2011. Zero-carbon homes: impact assessment. ISBN 9781409829645.Department of Communities and Local Government, May 2011. Available at: https://www.gov.uk/government/publications/zero-carbonhomes-impact-assessment

de Dear, R., Brager, G., and Cooper, D., 1997. Developing an adaptive model of thermal comfort and preference. Final Report, ASHRAE RP-884. Sidney, Berkeley, March 1997.

DEFRA, 2007. Climate Change Bill Summary. 2007. Available at: www.defra.gov.uk/environment/climatechange/uk/legislation/pdf/CCBill-summary.pdf (accessed June 07) p2 DEFRA. 2010. UK Climate Projections User Interface, 5km grid (available) http://ukclimateprojectionsui.defra.gov.uk/ui/docs/grids/wg_5km/index.php

Deutscher, P., Elsberger, M., and Rouval, L., 2000. Sommerlicher Warmeschutz. Eine einheitliche Methodik fur die Anforderungen an den winterlichen und sommerlichen Warmeschultz. Bauphysik 22, 2 (2000) 114-120 and 22,3 (2000) 178-184

DIN 1946-2, 1994. Raumlufttechnik; Gesundheitstechnische Anforderungen (VDI-Lüftungsregeln). Issued January 1994 (Withdrawn). Available at: http://www.beuth.de/en/standard/din-1946-2/2204739

DIN 4108-2, 2013. Wärmeschutz und Energie-Einsparung in Gebäuden - Teil 2: Mindestanforderungen an den Wärmeschutz. Issued Feb 2013. Available at: http://www.beuth.de/en/standard/din-41082/167922321?SearchID=511169764

DS/CEN/CR 1752, 2001. Ventilation for buildings - Design criteria for the indoor environment. Danish Standards Association.

Donatelli, M., Confalonieri, R., Cerrani, I., Fanchini, D., Acutis, M., Tarantola, S., and Baruth, B., 2009. LUISA (Library User Interface for Sensitivity Analysis): a generic software component for sensitivity analysis of biophysical models. 18th World IMACS/ MODSIM Congress. Cairns, Australia 13-17 July 2009. Available at: http://mssanz.org.au/modsim09 
EN ISO 7730, 2006. Moderate thermal environments- determination of the PMV and PPD indices and specifications for thermal comfort. ISO, Geneva.

EN 15251, 2007. Indoor environmental input parameters for design and assessment of energy performance of buildings addressing indoor air quality, thermal environment, lighting and acoustics. Beuth, Berlin, August 2007.

EU, 2010. Directive 2010/31/EU of the European Parliament and of the council of 19 May 2010 on the energy performance of buildings (recast). Official Journal of the European Union, Volume 53, 18 June 2010. ISSN 1725-2555 Available at: http://ec.europa.eu/energy/efficiency/doc/buildings/info_note.pdf

Fanger, P., 1970. Thermal Comfort. Analysis and Applications in Environmental Engineering. McGraw-Hill, 1970

Feist, W., 1994. Innere Gewinne warden überschätzt. Beitrag in Sonnenenergie und Wärmetechnik 1/94

Feist, W., Peper, S., Kah, O., von Oesen, M., 2005. Climate Neutral Passive House Estate in HannoverKronsberg: Construction and Measurement Results. PEP Project Information No.1. ProKlima, Hannover 2005. Available at: http://www.solaripedia.com/files/176.pdf

Feist, W., 2007. Passivhäuser in der Praxis. In: Fouad, Nabil (ed.): Bauphysik-Kalender 2007. Ernst and Sohn, Berlin 2007

Feist, W., Pfluger, R., Schnieders, J., Kah, O., Kaufman, B., Krick, B., Bastian, Z., and Ebel, W., 2012. Passive House Planning Package Version 7 (2012): Requirements for Quality Approved Passive Houses. 3rd revised edition June 2012. Passivhaus Institute, Darmstadt.

Feist, W., Hasper, W., Horner, M., Kah, O., Kaufman, B., Krick, B., Schnieders, J., and Schweitzer, K., 2012 b. Sommerverhalten von Nichtwohngebäuden im Passivhaus-Standard; Projekterfahrungen und neue Erkenntnisse. Protokollband 41. 1st Edition June 2012

Ford, B., Schiano-Phan, R., and Zhongcheng, D., 2007. The Passivhaus standard in European warm climates: design guidelines for comfortable low energy homes. Part 2. National proposals in detail: Passivhaus UK. Passive-on project. EIE/04/091/S07.38644, July 2007

Garcia Sanchez, D., Lacarrière, B., Musy, M., and Bourges, B., 2012. Application of sensitivity analysis in building energy simulations : Combining first and second - order elementary effects methods. Energy and Buildings (2012). Available at: www.elsevier.com/locate/enbuild

Ginkel, J.,T., van., 2007. Inventarisatie woninggerelateerade gezondheidskachten in Vathorst, report for Municipality of Amersfoort, Delft, Netherlands, OTB. 
Greenberg, J., Bromberg, J., Reed, C., Gustafson, T., Beauchamp, R., 1983. The epidemiology of heat- related deaths, Texas - 1950, 1970-79, and 1980. Am J Public Health 73(7); 805-807 (1983)

Hacker, J., De Saulles, T., Minson, A., and Holmes, M., 2008. Embodied and operational carbon dioxide emissions from housing: a case study on the effects of thermal mass and climate change. Energy and Buildings, Volume 40, Issue 3 (2008); 375-384

Hajat, S., Kovats, R., Atkinson, R., and Haines, A., 2002. Impact of Hot Temperatures on death in London: a time series approach. J. Epidemiol. Community Health 2002; 56: 367-72

Hales, S., Salmond, C., and Town, G., 2000. Daily mortality in relation to weather and air pollution in Chritchurch, New Zealand. Aust NZ J Public Health 2000; 24: 89-91

Hasselaar, E., 2008. Health risk associated with passive houses: An exploration. Indoor Air conference 17-22 August 2008. Copenhagen, Denmark. Paper ID: 689

Henderson, J., 2009. Review of Auxiliary energy use and the internal heat gains assumptions in SAP 2009. BRE, March 2009

Hermelink, A., and Hübner, H., 2003. Is One Litre Enough? Tenants' Satisfaction in Passive Houses. Proceedings of ECEEE 2003 Summer Study, ECEEE Stockholm 2003

Hermelink, A., 2004. Werden Wünsche wahr? Temperaturen in Passivhäusern für Mieter. In: Arbeitskreis kostengünstige Passivhäuser, Protokollband Nr. 25, Temperaturdifferenzierung in der Wohnung, Passivhaus Institut, Darmstadt 2004.

HM Government, 2010. Building Regulation Approved Document L1A, 2010. Conservation of fuel and power for new dwellings, HM Government, Available at:

http://www.planningportal.gov.uk/uploads/br/BR_PDF_ADL1A_2010.pdf

HM Government, 2011. The Carbon Plan. November 2011. Available at:

https://www.gov.uk/government/uploads/system/uploads/attachment_data/file/47621/1358-the-carbonplan.pdf

Hopfe, C., and Hensen, J., 2011. Uncertainty analysis in building performance simulation for design support. Energy and Buildings, 43(2011) Issue 10; 2798-2805, ISSN 0378-7788, 10.1016/j.enbuild.2011.06.034. Available at: http://www.sciencedirect.com/science/article/pii/S0378778811002830

Hu and Augenbroe, G., 2012. A stochastic model based energy management system for off-grid solar houses. Building and Environment 50 (2012): 90-103 Available at: www.elsevier.com/locate/buildenv 
Humphreys, M., and Nicol, F., 2002. The validity of ISO-PMV for predicting comfort votes in every-day thermal environments. Energy and Buildings 34, 6 (2002) 667-684

IES, 2009. Integrated Environmental Design Solutions Ltd. ApacheSim software validation history in accordance with CIBSE: AM11:1998. Available at:

http://www.iesve.com/downloads/help/Thermal/Reference/AM11ChecklistAPACHE.pdf

Inkarojit, V., 2005. Balancing Comfort: Occupants' Control of Window Blinds in Private Offices. Ph. D. thesis, University of California, Berkeley, 2005

IPCC, 2007. IPCC Fourth Assessment Report. Climate Change 2007 - Synthesis Report. Available at: http://www.ipcc.ch/publications_and_data/ar4/syr/en/contents.html

iPHA, 2013a. International Passive House Association, The Passive House - definition. Available at: http://passipedia.passiv.de/passipedia_en/basics/the_passive_house_-_definition

iPHA, 2013b. International Passive House Association, Passive House Buildings Project Database. Available at: http://www.passivhausprojekte.de/projekte.php?search=2

Isaksson, C., and Karlson, F., 2006. Indoor Climate in low energy houses - an interdisciplinary investigation. Building and Environment 41 (2006), pp. 1678-1690

Janson, U. 2010. Passive Houses in Sweden - From design to evaluation of four demonstration projects. Report EBD-T-10/12, ISBN 978-91-85147-46-5, Lund University, Faculty of Engineering LTH.

Available at: http://www.ebd.Ith.se/fileadmin/energi_byggnadsdesign/images/Publikationer/Doc_avhandling_ UJ_Bok_webb.pdf

Jenkins, G., Perry, M., and Prior, M., 2007. The climate of the United Kingdom and recent trends. Met Office Hadley Centre, Exeter, EX1 3PB, UK.

Jenkins, G., Murphy, J., Sexton, D., Lowe, J., Jones, P., and Kilsby, C., 2010. UK Climate Projections: Briefing report. Met Office Hadley Centre, Climatic Research Unit University of East Anglia, and University of Newcastle. Version 2, December 2010

Johnson, H., Kovats, R., McGregor, G., Stedman, J., Gibbs, M., and Walton, H., 2005. The impact of the 2003 heat wave on daily mortality in England and Wales and the use of rapid weekly mortality estimates. Eurosurveillance: European Communicable Disease Journal. Vol.10 (7-9) Jul-Sep 2005 pp. 168-171 Jones, G., Stott, P., and Christidis, N., 2008. Human contribution to rapidly increasing frequency of very warm Northern Hemisphere summers. Journal of Geophysical Research: Atmospheres 113. D02109, doi:10.1029/2007JD008914 
Kendon, M., 2012. Personal email correspondence from National Climate Information Centre. 05/08/2012

Kim, S., and Augenbroe, G., 2013. Uncertainty in developing supervisory demand-side controls in buildings: A framework and guidance, Automation in Construction (2013), http://dx.doi.org/10.1016/j.autcon.2013.02.001

Kodra, E., Steinhaeuser, K., and Ganguly, A., 2011. Persisting cold extremes under 21st century warming scenarios. Geophysical Research Letters 38, L08705, doi: 10.1029/2011GL0471

Kovats, S., and Hajat, S., 2008. Heat stress and public health: A critical review. Annual Review of Public Health (2008) 29(9) 1-9.15

Larsen, U., 1990. The effects of monthly temperature fluctuations on mortality in the United States from 1921 to 1985. Int J Biometeorol 1990; 34: 136-45

Larsen, T.S. and Jensen, R.L., 2011. Comparison of measured and calculated values for the indoor environment in one of the first Danish Passive houses. Proceedings of Building Simulation 2011: 12th Conference of International Building Performance Simulation Association, Sydney, Australia, 14-16 November 2011. Available at: www.ibpsa.org

Levermore, G, and Parkinson J. 2006. Analyses and algorithms for new Test Reference Years and Design Summer Years for the UK. Building Serv. Eng. Res. Technol., 2006; 27: 311-325.

Littlefair, P., 2005. Avoiding air conditioning. Constructing the Future (24), 11.

Lomas, K., and Giridharan, R., 2012. Thermal comfort standards, measured internal temperatures and thermal resilience to climate change of free running buildings: A case-study of hospital wards. Building and Environment 55 (2012) 57-72. Available at: www.elsevier.com/locate/buildenv

McKay, M., Beckman, R., and Conover, W., 1979. A comparison of three methods for selecting values of input variables in the analysis of output from a computer code. Technometrics 21(1979):2; 239-245

McLeod, R., Hopfe, C., and Rezgui, Y., 2012. A proposed method for generating high resolution current and future climate data for Passivhaus design. Energy and Buildings 55 (2012) 481-493. Available at: www.elsevier.com/locate/enbuild

Meinshausen, M., 2006. What does a $2^{\circ} \mathrm{C}$ target mean for greenhouse gas concentrations? A brief analysis based on multi-gas emission pathways and several climate sensitivity uncertainty estimates. In Avoiding dangerous climate change (eds H. J. Schellnhuber, W. Cramer, N. Nakicenovic, T. Wigley \& G. Yohe), pp. 253279. Cambridge, UK: Cambridge University Press.

Met Office, 2011. UKCP09 gridded observation data. Available at: http://www.metoffice.gov.uk/climatechange/science/monitoring/ukcp09/faq.html\#faq 
Mlecnik, E., Schütze,T., Jansen,S., de Vries, G., Visscher, H., and van Ha, A., 2012. End-user experiences in nearly zero-energy houses. Energy and Buildings, Volume 49, June 2012, Pages 471-478. Available at: http://www.sciencedirect.com/science

Morris, M., 1991. Factorial sampling Plans for Preliminary Computational Experiments. Technometrics, Vol.33 (May, 1991) No.2; 161-174

Na, W., Jang, J., Lee, K., Kim, H., Jun, B., Kwon, J., and Jo, S., 2013.The Effects of Temperature on Heat-related Illness According to the Characteristics of Patients During the Summer of 2012 in the Republic of Korea. J Prev Med Public Health. 2013 January; 46(1): 19-27.Published online 2013 January 31. doi:

10.3961/jpmph.2013.46.1.19. PMCID: PMC3567322

Nakai, S., Itoh, T., and Morimoto, T., 1999. Deaths from heat stroke in Japan: 1968-1994. Int J Biometeorol 1999; 43:124-7

NHBC, 2012a. Overheating in new homes: A review of the evidence. Research undertaken by Dengel, A., and Swainson, M., on behalf of NHBC Foundation. NF 46, ISBN 978-1-84806-306-8. November 2012

Nicol, F., 2001. Characterising occupant behaviour in buildings: towards a stochastic model of occupant use of windows, lights, blinds, heaters and fans. Proceedings of seventh international IBPSA conference, Rio 2001, pp. 1073-1078

Nicol, F., Raja, I., Alludin, A., and Gul, J., 1999. Climatic variations in comfortable temperatures: the Pakistan projects. Energy and Buildings 30 (1999) 261-279

Nicol, F., Hacker, J., Spires, B., and Davies, H., 2009. Suggestion for new approach to overheating diagnostics. Building Research and Information, 37: 4, 348-357

NRC, 1991. Human exposure assessment for airborne pollutants: advances and opportunities.. Committee on Advances in Assessing Human Exposure to Airborne Pollutants, National Research Council. Washington, DC., National Academy Press, 1991

ODPM, 2006. Housing Health and Safety rating System (HHSRS): Operating Guidance. Office of the Deputy Prime Minister, London, 2006.

Ofgem, 2012. Electricity Capacity Assessment. Ofgem report to Government. Reference 126/125. October 2012. Available at: www.ofgem.gov.uk/

O’Neill, M., Zanobetti, A., and Schwartz, J., 2005. Disparities by race in heat-related mortality in four US cities: the role of air-conditioning prevalence. Journal of Urban Health 82, 191-197. 
ONS, 2003. Office of National Statistics UK. Summer mortality - deaths up in August heat wave. London: ONS, October 2003. Available at: http://www.statistics.gov.uk/cci/nugget.asp?id=480

ONS, 2005. The Time Use Survey, 2005. Amended 31st August 2006. Office of National Statistics, London. Available at: http://www.timeuse.org/files/cckpub/lader_short_and_gershuny_2005_kight_diary.pdf ONS, 2012. Population Aging in the United Kingdom, its Constituent Countries and the European Union. March 2012. Available at: http://www.ons.gov.uk/ons/dcp171776_258607.pdf

Ormandy, D., and Ezratty, V., 2012. Health and thermal comfort: from WHO guidance to housing strategies. Energy Policy 49 (2012) 116-121. Available at: www.elsevier.com/locate/enpol

Orme, M., and Palmer, J., 2003. Control of overheating in future housing - Design guidance for low energy strategies. St. Albans: DTI Partners in Innovation Programme.

Ostro, B., Rauch, S., Green, R., Malig, B., and Basu, R., 2010. The effects of temperature and use of air conditioning on hospitalizations. American Journal of Epidemiology 172, 1053-1061

Passive House Builders, 2013. Personal correspondence, and data logger analysis, for Limerick and Galway City Passivhaus projects.

Persson, J., and Westermark, M., 2012. Phase Change material storage for Swedish Passive House. Energy and Buildings 54 (2012) 490-495. Available at: www.elsevier.com/locate/enbuild

Rahmstorf, S., and Coumou, D., 2011. Increase of extreme events in a warming world. Proceedings of the National Academy of Sciences of the United States of America 108, 17905-17909.

Raja, I., Nicol, F., McCartney, K., and Humphries, M., 2001. Thermal Comfort: Use of controls in naturally ventilated buildings. Energy and Buildings 33 (2001) 235-244

Raymann, R., Swaab, D., and van Someren, E., 2008. Skin deep: enhanced sleep depth by cutaneous temperature manipulation. Brain, 131 (2): 500-513

Rodrigues, L., 2009. An investigation into the use of thermal mass to improve comfort in British housing. In Department of Architecture and Built Environment, Nottingham University

Rodrigues, L., and Gillot, M., 2011. The summer performance of the BASF house. In PLEA $2011-27$ th Conference on Passive and Low Energy Architecture. Louvain-la-Neuve. Belgium. Presses universitaires de Louvain 
Rodrigues, L., Gillot, M., and Tetlow, D., 2013. The summer overheating potential in a low- energy steel frame house in future climate scenarios. Sustainable Cities and Society 7 (2013) 1-15. Available at www.elsevier.com/locate/scs

Rooney, C., McMichael, A., Kovats, R., and Coleman, M., 1998. Excess mortality in England and Wales, and in Greater London, during the 1995 heat wave. J Epidemiol Community Health. 1998; 52: 482-486

RoSPA, 2005. Can The Home Ever Be Safe? The need to improve safety in the built environment of homes and gardens. Royal Society for the Prevention of Accidents, 2002 (revised edition. February 2005). Available at: http://www.rospa.com/homesafety/Info/can-the-home-ever-be-safe.pdf

Rouvel, L., 1997. Thermische Bewertung von Gebäuden unter sommerlichen Randbedingungen.

Gesundheitsingenieur 118, 2 (1997) 65-74

Ruud, S., and Lundin, L., 2004. Bostadhus utan traditionellt uppvarmningssytem -resultat fran tva ars matningar. SP Report 2004:31, SP Technical Research Institute of Sweden

Saltelli, A., Tarantola, S., Campolongo, F., and Ratto, M., 2004. Sensitivity Analysis in Practice. A Guide to Assessing Scientific Models. Published by: John Wiley and Sons Ltd, Chichester England PO19 8SQ. March 2004 Saltelli, A., Ratto, M., Andres, T., Campolongo, F., Cariboni, J., Gatelli, D., Saisana, M., and Tarantola, S., 2008. Global Sensitivity Analysis: The Primer. Published by: John Wiley and Sons Ltd, Chichester England PO19 8SQ. ISBN 978-0-470-05997-5. November 2008

Samuelson, M., and Lüddeckens, T., 2009. Passivhus ur en brukares perspektiv. Student Thesis, Faculty of Mathematics/Science/Technology, School of Technology and Design, Växjö University, Sweden, Available at: http://Inu.diva-portal.org/smash/record.jsf?pid=diva2:220810

Schmitt, Y., Dal Savio, S., and Sparber, W., 2007. Monitoring of a multi-family passive house in South Tyrol, Italy. Proceedings of 11th International Conference on Passive Houses 2007. 13-14 April Bregenz, Austria.

Schneiders, J., Feist, W., Pfluger, R., and Kah, O., 2001. CEPHEUS - Wissenschaftliche Begleitung und Auswertung, Endbericht, CEPHEUS Projektinformation Nr.22, Fachinformation PHI-2001/9, Darmstadt, Passivhaus Institut, July 2001

Schnieders, J., and Hermelink, A., 2006. CEPHEUS results: measurement and occupants' satisfaction provide evidence for Passive Houses being an option for sustainable building. Energy Policy 34 (2006) 151-171

Schnieders, J., 2005. A first guess passive home in southern France. Passive-On Project report. Available at: www.maison-passive-nice.fr/documents/FirstGuess_Marseille.pdf 
Schnieders, J., 2009. Passive Houses in South West Europe. A quantitative investigation of some passive and active space conditioning techniques for highly energy efficient dwellings in the south West European region. 2nd corrected edition 2009. Available at: www.passiv.de

Stedman, J., The predicted number of air pollution related deaths during the August 2003 heatwave. Atmos Environ. 2004; 38: 1087-1090

Struck, C., 2012. Uncertainty propagation and sensitivity analysis techniques in building performance simulation to support conceptual building and system design. PhD thesis, University of Technology Eindhoven. IBN 978-90-386-3242-1

Taylor, M., and Morgan, L., 2011. Ventilation and good indoor air quality in low energy homes:

Finding proven good practice. Good Homes Alliance, Nov 2011. Available at:

http://www.goodhomes.org.uk/downloads/news/VIAQ/final.pdf

Thomas, M., Sing, H., Belenky, G., Holcomb, H., Mayberg, H.,Dannals, D., Wagner, W., Thorne, D., Popp, K., Rowland, L.,Welsh, A. and Redmond, D., 1998. Brain and behavior changes during sleep deprivation. Proceedings of the Human Factors and Ergonomics Society (Vol. 2) Human Factors and Ergonomics Society, Santa Monica, 88, 1998: 1608

Vardoulakis, S., and Heaviside, C., 2012. Health Effects of Climate Change in the UK 2012: Current evidence, recommendations and research gaps. September 2012. ISBN 978-0-85951-723-2. Available at: www.hpa.org.uk

Voss, K., Löhnert, G., Herkel, S., Wagner, A., and Wambsganß (Eds), 2005. Bürogeb ude mit Zukunft. TÜVVerlag, Köln 2005.

Wagner, W., and Mauthner, F., 2008a. Energietechnische und baubiologische Begleituntersuchung der Bauprojekte - Berichsteil Passivwohnhausanlage Utendeorfgasse, AEE Institut fur Nachhaltige Technologien, Gleisdorf, Austria, 2008.

Wagner, W., and Mauthner, F., 2008b. Energietechnische und baubiologische Begleituntersuchung der Bauprojekte - Berichsteil Passivwohnhausanlage Roschegasse, AEE Institut fur Nachhaltige Technologien, Gleisdorf, Austria, 2008.

Wainwright, S., Buchanan, S., Mainzer, M., Parrish, R., and Sinks, T., 1999. Cardiovascular mortality-the hidden peril of heat waves. Prehospital Disaster Med 14(4); 222-231

Wang, X., Potter, S., Williams, J., Atwood, J., and Pitts, T., 2006. Transactions of the American Society of Agricultural and Biological Engineers. Vol. 49(2006): 3; 679-688. ISSN 0001-2351

Watts, A., 1971. Hypothermia in the aged: a study of the role of cold-sensitivity. Environmental Health Research 5: 119-126 
WHO, 1987. Health Impacts of Low Temperatures: Report on a WHO Meeting. World Health Organization for Europe, Copenhagen 11-14 November 1985. Available at:

http://whqlibdoc.who.int/euro/ehs/EURO_EHS_16.pdf

WHO, 1990. Indoor Environment: Health Aspects of Air Quality, Thermal Environment, Light and Noise. World Health Organization. Available at: http://whqlibdoc.who.int/hq/1990/WHO_EHE_RUD_90.2.pdf

Wilby, R. 2003. Past and projected trends in London's urban heat island. Weather 2003; 58: pp. 25-260

Wilson, W., 2008. Housing Health and Safety Rating System (HHSRS). Standard Note SN/SP/1917 3. Social Policy Section, House of Commons Library, November 2008

Wright, A., Young, A., and Natarajan, S., 2005. Dwelling temperatures and comfort during the August 2003 heat wave. Building Serv. Eng. Res. Technol. 26, 4 (2005) pp. 285-300

Zero Carbon Hub (ZCH), 2009. Zero Carbon Hub Task Group: Defining a Fabric Energy Efficiency Standard for Zero Carbon Homes: Task Group Recommendations November 2009. Available at:

http://www.zerocarbonhub.org/resourcefiles/ZCH-Defining-A-Fabric-Energy-Efficiency-Standard-Task-GroupRecommendations.pdf (Accessed August 20, 2010).

Zero Carbon Hub (ZCH), 2010a. Carbon Compliance for Tomorrow's New Homes, A Review of the Modelling Tool and Assumptions, Overview of Findings and Recommendations, July 2010. Available at http://www.zerocarbonhub.org/resourcefiles/

Zero Carbon Hub (ZCH), 2011. Carbon Compliance setting an appropriate limit for zero carbon new homes: findings and recommendations. Zero Carbon Hub, Feb 2011. Available at http://www.zerocarbonhub.org/definition.aspx?page=8 